\title{
Specific Inhibition of Phosphodiesterase-4B Results in Anxiolysis and Facilitates Memory Acquisition
}

\begin{abstract}
Alexander McGirr*, I,2, Tatiana V Lipina ${ }^{2}$, Ho-Suk Mun ${ }^{2,3}$, John Georgiou ${ }^{2}$, Ahmed H Al-Amri $^{4,5}$, Enoch Ng ${ }^{2,6}$, Dongxu Zhai ${ }^{7}$, Christina Elliott ${ }^{8}$, Ryan T Cameron ${ }^{8}$, Jonathan GL Mullins ${ }^{9}$, Fang Liu ${ }^{7}$, George S Baillie ${ }^{8}$, Steven J Clapcote ${ }^{*, 4}$ and John C Roder 2,10

'Department of Psychiatry, University of British Columbia, Vancouver, British Columbia, Canada; 'Lunenfeld-Tanenbaum Research Institute, Mount Sinai Hospital, Toronto, Ontario, Canada; ${ }^{3}$ Department of Medical Genetics, University of Toronto, Toronto, Ontario, Canada; ${ }^{4}$ School of Biomedical Sciences, University of Leeds, Leeds, UK; ${ }^{5}$ National Genetic Centre, Royal Hospital, Muscat, Oman; ${ }^{6}$ Institute of Medical Science, University of Toronto, Toronto, Ontario, Canada; ' Department of Neuroscience, Centre for Addiction and Mental Health, Toronto, Ontario, Canada; ${ }^{8}$ Institute of Cardiovascular and Medical Sciences, College of Medical, Veterinary and Life Sciences, University of Glasgow, Glasgow, UK; ${ }^{9}$ Institute of Life Science, College of Medicine, Swansea University, Swansea, UK; ${ }^{10}$ Department of Physiology, University of Toronto, Toronto, Ontario, Canada
\end{abstract}

\begin{abstract}
Cognitive dysfunction is a core feature of dementia and a prominent feature in psychiatric disease. As non-redundant regulators of intracellular cAMP gradients, phosphodiesterases (PDE) mediate fundamental aspects of brain function relevant to learning, memory, and higher cognitive functions. Phosphodiesterase-4B (PDE4B) is an important phosphodiesterase in the hippocampal formation, is a major Disrupted in Schizophrenia I (DISCI) binding partner and is itself a risk gene for psychiatric illness. To define the effects of specific inhibition of the PDE4B subtype, we generated mice with a catalytic domain mutant form of PDE4B (Y358C) that has decreased ability to hydrolyze CAMP. Structural modeling predictions of decreased function and impaired binding with DISCI were confirmed in cell assays. Phenotypic characterization of the PDE4B ${ }^{Y 358 C}$ mice revealed facilitated phosphorylation of $\mathrm{CREB}$, decreased binding to DISCI, and upregulation of DISCI and $\beta$-Arrestin in hippocampus and amygdala. In behavioral assays, PDE4B ${ }^{Y 358 C}$ mice displayed decreased anxiety and increased exploration, as well as cognitive enhancement across several tests of learning and memory, consistent with synaptic changes including enhanced long-term potentiation and impaired depotentiation ex vivo. PDE4B ${ }^{\text {Y358C }}$ mice also demonstrated enhanced neurogenesis. Contextual fear memory, though intact at $24 \mathrm{~h}$, was decreased at 7 days in PDE4B ${ }^{Y 358 C}$ mice, an effect replicated pharmacologically with a non-selective PDE4 inhibitor, implicating CAMP signaling by PDE4B in a very late phase of consolidation. No effect of the PDE4B ${ }^{Y 358 C}$ mutation was observed in the prepulse inhibition and forced swim tests. Our data establish specific inhibition of PDE4B as a promising therapeutic approach for disorders of cognition and anxiety, and a putative target for pathological fear memory. Neuropsychopharmacology (20 I6) 4I, I080-1092; doi:I0.1038/npp.20 I5.240; published online 2 September 2015
\end{abstract}

\section{INTRODUCTION}

Cognitive dysfunction is a core feature of dementia and a prominent feature in major psychiatric disorders, such as mood and chronic psychotic disorders. Consequently, there is a large unmet need for cognition-enhancing drugs. The second messenger cyclic adenosine monophosphate (cAMP) mediates fundamental aspects of brain function relevant to learning, memory, and higher cognitive functions (Richter et al, 2013). Memory formation relies on expression of genes upregulated by the transcription factor CREB (cAMP response element binding protein), which is activated when phosphorylated by PKA (protein kinase A) downstream of

*Correspondence: Dr A McGirr, Department of Psychiatry, University of British Columbia, Vancouver, British Columbia, Canada V6T 2AI, E-mail: alexander.mcgirn@alumni.ubc.ca or Dr SJ Clapcote, School of Biomedical Sciences, University of Leeds, Leeds LS2 9JT, UK, Tel: +44 (0) I 13 343304 I, E-mail: s.j.clapcote@leeds.ac.uk

Received 18 March 20 I5; revised 30 July 20 I5; accepted 3 August 20 I5; accepted article preview online 14 August 2015
cAMP. As a consequence, cAMP-specific phosphodiesterase enzymes, the sole regulators of cAMP gradients and ultimately CREB, are promising targets for the development of cognition-enhancing drugs (Ghavami et al, 2006; Richter et al, 2013).

The PDE4 family is cAMP-specific and comprises four subtypes (A-D). The expression patterns of individual PDE4 subtypes are clearly distinct at the regional and cellular level, suggesting that PDE4 subtypes serve non-redundant functions. Non-subtype-selective brain-penetrant PDE4 inhibitors (targeting all of four subtypes), such as rolipram, have shown therapeutic benefit in preclinical models of psychiatric and neurological diseases (Ghavami et al, 2006; Richter et al, 2013). These models include memory and cognition impairments induced by the $N$-methyl-D-aspartate receptor antagonist MK-801 (Davis and Gould, 2005; Zhang et al, 2000), cerebral ischemia-induced neuron loss and associated memory deficits in rats (Li et al, 2011a), age-related memory deficits (de Lima et al, 2008), and working, reference and 
associative memory deficits in a transgenic mouse model of Alzheimer's disease (Gong et al, 2004).

However, non-selective PDE4 inhibitors are poorly tolerated in humans owing to nausea and emesis arising from inhibition of PDE4 in the brain stem (Mori et al, 2010) and gut (Menniti et al, 2006) at doses required for clinical effectiveness. Several lines of evidence suggest that these adverse effects are related to PDE4D, but not PDE4B (Robichaud et al, 2002). Indeed, despite comparable efficacy on other indicators, PDE4B-selective inhibitors may require doses approaching 100-fold that of PDE4D-selective agents to result in emesis, despite similar effect on other measures (Naganuma et al, 2009). Given the poor tolerability of nonselective agents, the elucidation of individual PDE4 subtype function has emerged as a strategy to guide the development of subtype-selective agents with maximal therapeutic utility and tolerability. This has, in part, been facilitated by the availability of knock-out (KO) mice deficient in individual PDE4 subtypes.

PDE4 subtypes are constitutively active enzymes containing a highly conserved catalytic domain, and then divided into categories defined by the presence of two unique, conserved domains: Upstream Conserved Region 1 (UCR1) and 2 (UCR2) (Zhang, 2009). The cAMP hydrolytic activity of PDE4B is facilitated and inhibited by PKA (Baillie, 2009) and ERK (extracellular signal-related kinase; Baillie et al, 2000), respectively. The catalytic domain and UCR1 contain phosphorylation sites for PKA and ERK, respectively. Five PDE4B isoforms have been identified in mammals: the long forms PDE4B1 (736 a.a.), 4B3 (721 a.a.) and 4B4 (659 a.a.), the short form 4B2 (564 a.a.), and the super-short form 4B5 (484 a.a.) (Cheung et al, 2007; Fatemi et al, 2008; Shepherd et al, 2003). The catalytic domain is common to all isoforms, whereas the long forms contain UCR1 and UCR2, the short form lacks UCR1, and the super-short form has only a portion of UCR2 (Zhang, 2009).

PDE4B is widely distributed throughout the brain in humans, monkeys, and rodents, with prominent expression in the cerebral cortex, limbic areas and diencephalon (Cherry and Davis, 1999; Lakics et al, 2010; Perez-Torres et al, 2000), as well as white matter tracts (Reyes-Irisarri et al, 2008). In cortex, the PDE4B1 isoform predominates, however in hippocampus and amygdala all isoforms are expressed (Reyes-Irisarri et al, 2008). Consistent with preclinical evidence of cognitive enhancement, changes in expression and subcellular localization of PDE4B in hippocampal neurons are associated with long-term potentiation (LTP) (Ahmed and Frey, 2005), considered one of the cellular mechanisms underlying learning and memory (Albensi et al, 2007). Moreover, $P d e 4 b \mathrm{KO}$ mice show an increase in the proliferation of neuronal cells in the hippocampal dentate gyrus (Zhang et al, 2008). Hippocampal slice preparations from Pde $4 b \mathrm{KO}$ mice show markedly enhanced basal postsynaptic responses and long-term depression (Rutten et al, 2011).

Pde $4 b \mathrm{KO}$ mice display a complex behavioral phenotype. They exhibit a moderately anxiogenic behavioral profile with decreased exploratory activity in the hole board and lightdark transition tests (Zhang et al, 2008), decreased locomotor activity in some open-field tests (Rutten et al, 2011; Siuciak et al, 2008; Zhang et al, 2008), and unaltered performance in the elevated plus maze (Siuciak et al, 2008). Pde $4 b \mathrm{KO}$ mice perform normally in the fear conditioning (Rutten et al, 2011) and passive avoidance tests (Siuciak et al, 2008; Zhang et al, 2008), and show unaltered shock sensitivity (Rutten et al, 2011) and nociceptive responses (Siuciak et al, 2008; Zhang et al, 2008). In the Morris water maze, $P d e 4 b \mathrm{KO}$ mice show normal spatial memory acquisition and retention (Rutten et al, 2011; Siuciak et al, 2008; Zhang et al, 2008), but impaired reversal learning (Rutten et al, 2011). Acoustic startle response is increased in $P d e 4 b \mathrm{KO}$ mice, while prepulse inhibition of the startle response is decreased (Siuciak et al, 2008). They show decreased immobility in the forced swim test (Siuciak et al, 2008; Zhang et al, 2008), but not in the tail suspension test (Zhang et al, 2008). As expected, however, Pde4b KO mice show resistance to the inhibitory effects of rolipram on conditioned avoidance response (Siuciak et al, 2007). Though complex, this phenotype provides support for a role for PDE4B in both memory and anxiety.

Several lines of evidence have implicated PDE4B in major psychiatric illness, most notably schizophrenia. Disruption of PDE4B was identified by a chromosomal translocation in two first cousins with schizophrenia (Millar et al, 2005). Subsequently, large population genetic analyses of schizophrenia have inconsistently implicated single-nucleotide polymorphisms within PDE4B (Fatemi et al, 2008; Guan et al, 2012; Kahler et al, 2010; Numata et al, 2008; Pickard et al, 2007; Rastogi et al, 2009; Tomppo et al, 2009). Although an established rare genetic cause of schizophrenia, emerging primate data provide preliminary support for a role for PDE4B in the regulation of synaptic and spine plasticity in the dorsolateral prefrontal cortex and working memory (Paspalas et al, 2013). Thus, decreased PDE4B expression in post-mortem brains of patients with schizophrenia (Fatemi et al, 2008) may reflect compensatory downregulation of PDE4B to increase synaptic plasticity and counter the cognitive deficits associated with this condition, a possibility that has not received significant attention.

DISC1 is a large scaffolding protein that has important interactions with PDE4B (Millar et al, 2005; Murdoch et al, 2007). It plays key roles in neuronal development, and is a well-established risk factor for major mental illness associated with cognitive dysfunction (Blackwood et al, 2001; Porteous et al, 2014). There are five PDE4 binding sites on $100-\mathrm{kDa}$ full-length DISC1; three of these sites are specific for PDE4B, while two potentially bind isoforms from each PDE4 subtype (Murdoch et al, 2007). In response to elevated cAMP levels, the shorter 71-kDa DISC1 isoform dissociates from PDE4B, whereas 100-kDa DISC1 does not dissociate, likely owing to more contact points with PDE4B (Murdoch et al, 2007).

Although poorly tolerated, non-subtype-selective PDE4 inhibitors have the potential to improve cognitive function, and several lines of evidence suggest that PDE4B may be a well-tolerated target for anxiety and cognitive enhancement. This study sought to determine the effects of specific inhibition of PDE4B by characterizing a catalytic domain mutant form of PDE4B (Y358C) that has decreased ability to hydrolyze cAMP. The catalytic domain of PDEs is an important pharmacological target, given limited homology between subtypes (Sung et al, 2003) and the well characterized relationship between existing PDE inhibitors and catalytic domains, notably clinically useful PDE5 inhibitors (Sung et al, 2003) and novel PDE4B inhibitors (Goto et al, 2013). We examined the neural and behavioral effects of the 

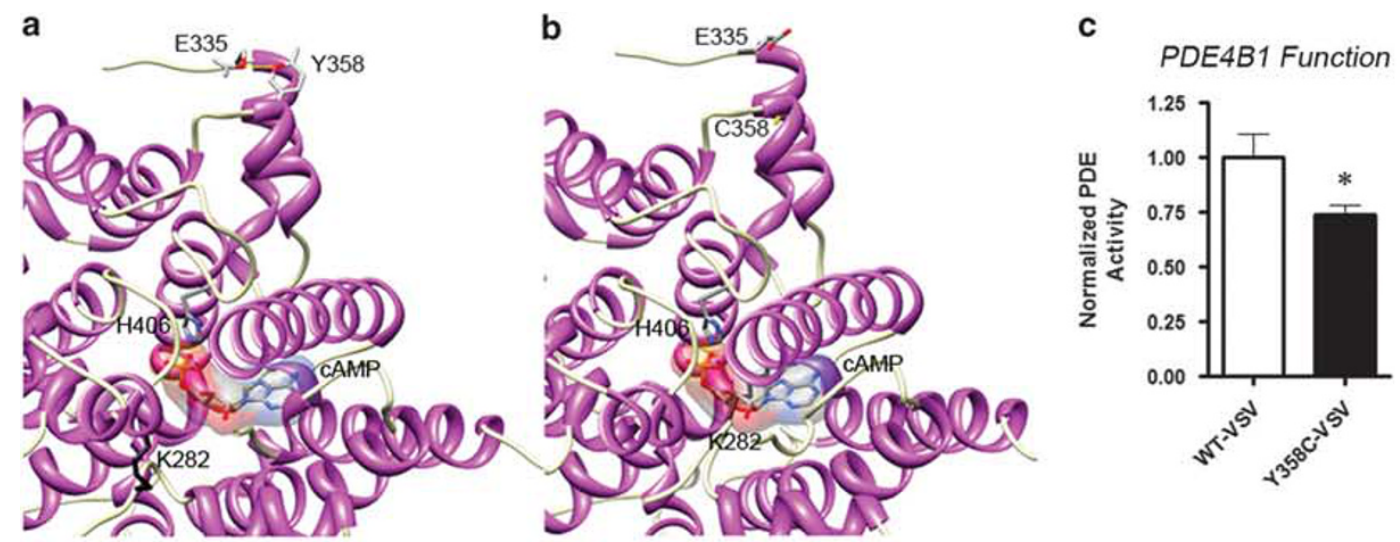

d

Hippocampus
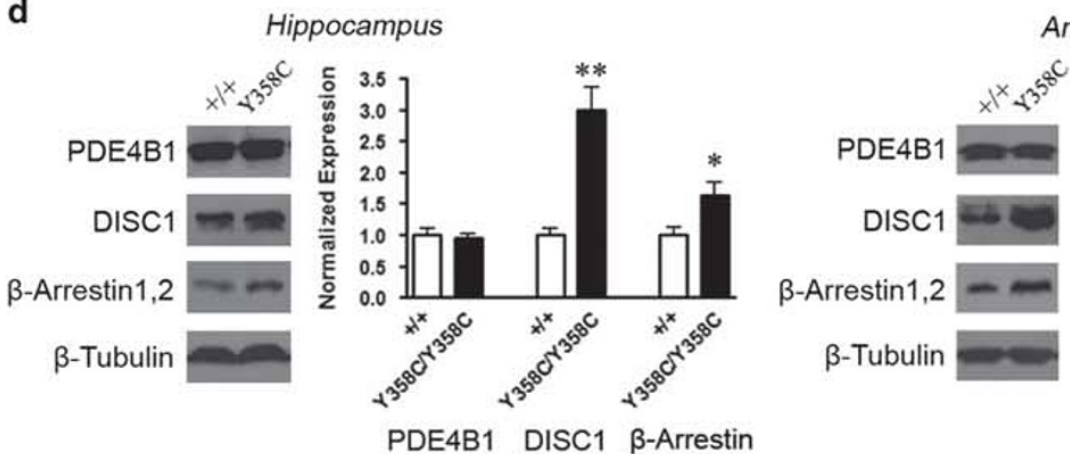

Amygdala

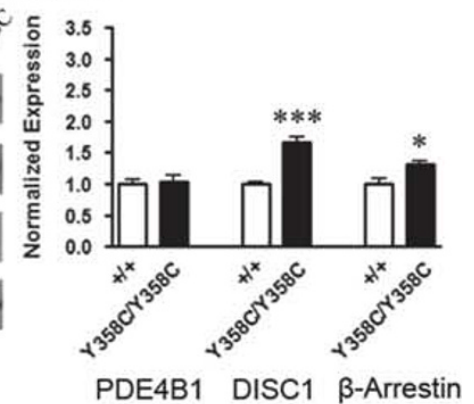

e
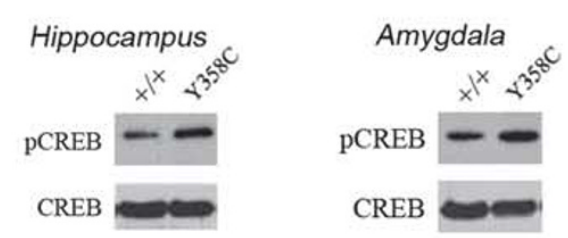

f

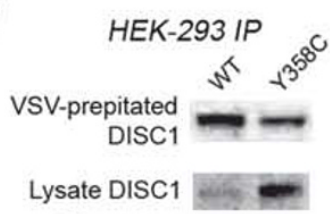

g Brain Co-IP
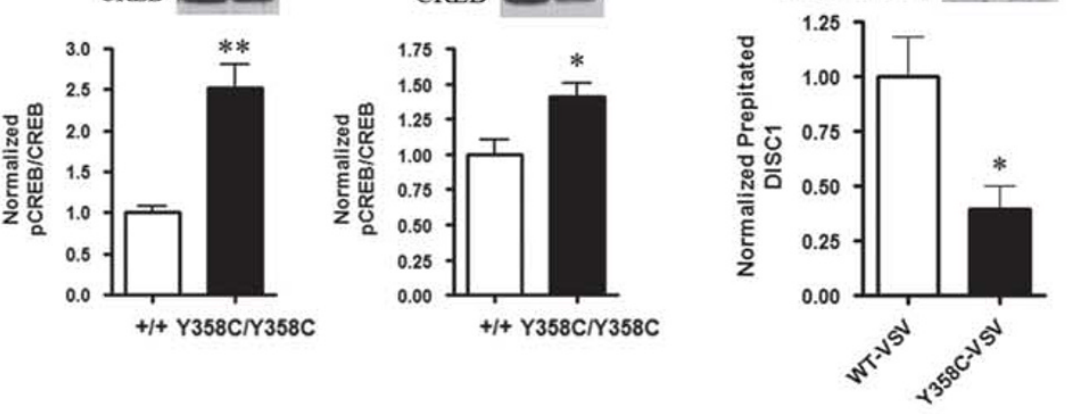

$$
+/+ \text { Y358C/Y358C }
$$
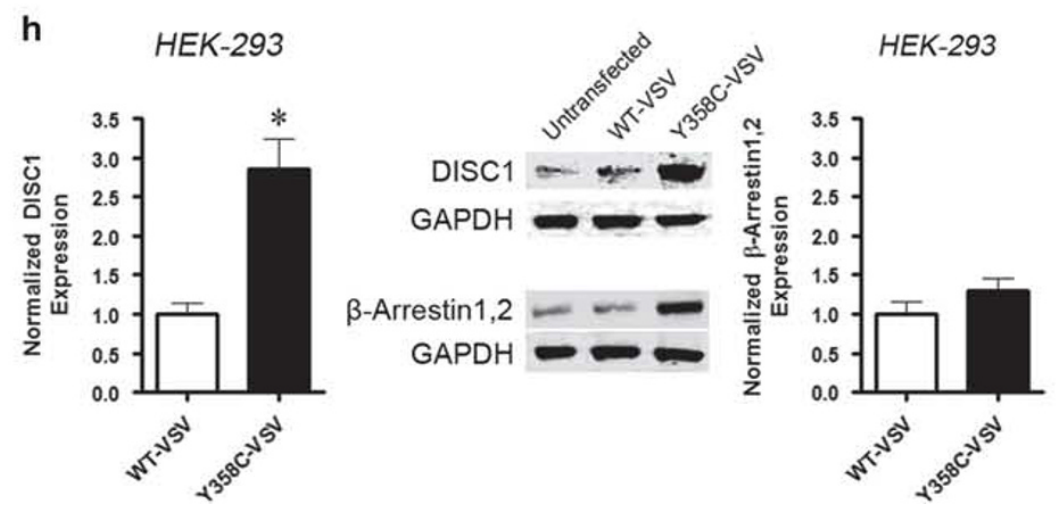
PDE4B-Y358C mutation in mice with a C57BL/6J genetic background. Our findings establish specific inhibition of $\mathrm{PDE} 4 \mathrm{~B}$ as a promising therapeutic approach for pathology affecting memory, anxiety, and fear memory.

\section{MATERIALS AND METHODS}

\section{Generation of PDE4B Mutant}

The catalytic domain of the PDE4B1 isoform (ENSMUSP00000102524) stretches from amino-acid residues (a.a.) 305-690 and is encoded by Pde4b exons 9-16 (Murdoch et al, 2007). We screened exon 10 (99 bp; a.a. 341-373) of $P d e 4 b$ in 7776 male $\mathrm{F}_{1}$ progeny of ENU-mutagenized BALB/ cAnN males and untreated $\mathrm{C} 3 \mathrm{H} / \mathrm{HeH}$ females in the MRC Harwell ENU DNA archive. In a single mouse (EMRCB/ $60.3 \mathrm{~d}$ ), we detected an adenine to guanine (A1073G) transition, corresponding to a $\mathrm{Tyr}^{358}$ (TAC) $\rightarrow$ Cys (TGC) (Y358C) exchange (Supplementary Figure 1a). The exon 10 sequences of the $\mathrm{BALB} / \mathrm{cAnN}$ and $\mathrm{C} 3 \mathrm{H} / \mathrm{HeH}$ parental strains are identical, suggesting that the $\mathrm{PDE} 4 \mathrm{~B}^{\mathrm{Y} 358 \mathrm{C}}$ mutation arose as a result of ENU administration. The tyrosine at position 358 is present in PDE4B isoforms 1-5 (Supplementary Figure $1 \mathrm{~b})$ and is conserved across vertebrate species and in mouse PDE4A (Supplementary Figure 1c).

Heterozygous $\mathrm{N}_{2}$ backcross progeny of the founder PDE4B ${ }^{\mathrm{Y} 358 \mathrm{C} /+} \quad(\mathrm{C} 3 \mathrm{H} / \mathrm{HeH} \times \mathrm{BALB} / \mathrm{cAnN}) \quad \mathrm{F}_{1}$ male and wild-type (WT) C57BL/6NTac females were backcrossed through the male and female lines to C57BL/6J for 10 generations before heterozygotes were intercrossed to generate homozygous mutant (PDE4B ${ }^{\mathrm{Y} 358 \mathrm{C} / \mathrm{Y} 358 \mathrm{C}}$ ) and $\mathrm{WT}$ $\left(\mathrm{PDE} 4 \mathrm{~B}^{+/+}\right)$littermates for phenotypic characterization. $\mathrm{PDE}_{4} \mathrm{~B}^{\mathrm{Y} 358 \mathrm{C} /+}$ frozen embryos are available from the MRC Mammalian Genetics Unit, UK (har.mrc.ac.uk).

Full methods are available in the Supplementary Methods.

Sex-differences were explored with two-way analysis of variance (ANOVA), however, no significant Genotype $\times$ Sex interactions were observed. For parsimonious interpretation, statistical differences are reported using Student's $t$-test, linear regression, repeated measures ANOVA, and Cox regression. Post hoc tests were performed using least significant difference when significant genotype ${ }^{\star}$ test interactions emerged in ANOVA or repeated measures ANOVA.

\section{RESULTS}

At the cAMP binding site, there is an interaction between the central phosphate group of cAMP and H406 in WT PDE4B1 (Figure 1a). Though the Y358 residue is located within the catalytic domain, it is neither at the site of cAMP binding nor rolipram binding (Richter et al, 2001). In the Y358C variant, a conformational change is predicted to the binding site by introducing a beta conformational bend bordering the cAMP binding cavity around K282. This severely disrupts the docking position of cAMP (Figure $1 \mathrm{~b}$ ) as the side chain of K282 bisects the binding site.

\section{PDE4B Y358C Alters cAMP Signaling and CREB Phosphorylation}

Using VSV-epitope-tagged human PDE4B1-Y358C and WT constructs expressed in HEK-293 cells, we found that PDE4B1-Y358C has a 27\% decreased ability to hydrolyze cAMP (Figure 1c). In mouse hippocampus, RT-PCR of PDE4B1-5 did not detect expression differences between $\mathrm{PDE} 4 \mathrm{~B}^{\mathrm{Y} 358 \mathrm{C} / \mathrm{Y} 358 \mathrm{C}}$ and $\mathrm{PDE} \mathrm{B}^{+/+}$mice (Supplementary Figure 2a). Similarly, western blotting did not detect genotypic differences in expression of PDE4B1 in the hippocampus, amygdala, prefrontal cortex, and nucleus accumbens associated with Y358C (Figure 1d; Supplementary Figure 2b and c). We probed the expression of PDE4A5, due to Y358 conservation in mouse, and PDE4D3, due to signs of upregulation in Pde $4 b \mathrm{KO}$ mice (Zhang et al, 2008), but found no genotypic differences (Supplementary Figure 2d). Hippocampal slices from PDE4B ${ }^{\mathrm{Y} 358 \mathrm{C} / \mathrm{Y} 358 \mathrm{C}}$ brains have similar levels of cAMP as PDE4B ${ }^{+/+}$, but showed a greater cAMP accumulation when challenged with forskolin alone or in combination with rolipram (Supplementary Figure 2e). As $\mathrm{PDE} 4 \mathrm{~B}$ regulates $\mathrm{cAMP}$ gradients and ultimately $\mathrm{CREB}$, we examined total expression of CREB and its phosphorylation ( $\mathrm{pCREB}$ ), finding increased pCREB/CREB in the hippocampi (2.5-fold) and amygdala (1.4-fold) of PDE4B ${ }^{\mathrm{Y} 358 \mathrm{C} / \mathrm{Y} 358 \mathrm{C}}$ mice (Figure 1e). The Y358C variant of PDE4B is thus normally expressed, but has reduced enzymatic activity, which in turn primes CREB signaling.

\section{Y358C Affects the PDE4B Partners DISC1 and $\beta$-Arrestin}

As Y358 occurs within one of the three DISC1 binding sites on PDE4B1 (a.a. 352-380) (Murdoch et al, 2007), we probed $100-\mathrm{kDa}$ DISC1 binding. Expression of the VSV-epitopetagged PDE4B1-Y358C and WT constructs in HEK-293 cells revealed decreased DISC1 immunoprecipitation (Figure 1f), which was paralleled in co-immunoprecipitation from PDE4B ${ }^{\mathrm{Y} 358 \mathrm{C} / \mathrm{Y} 358 \mathrm{C}}$ brains (Figure 1g). Western blotting revealed that the expression of DISC1 was unaltered in the prefrontal cortex and nucleus accumbens (Supplementary Figure $1 \mathrm{c}$ and $\mathrm{d}$ ), but was increased 3-fold in the hippocampus and 1.6-fold in the amygdala of PDE4B ${ }^{\mathrm{Y} 358 \mathrm{C} / \mathrm{Y} 358 \mathrm{C}}$

Figure I Biochemical consequences of PDE4B-Y358C mutation. (a) Wild-type PDE4BI with accessible Y358 and H406 interacting with cAMP. (b) Mutant PDE4BI with inaccessible 358C and disrupted cAMP-docking position. (c) CAMP hydrolytic function of VSV-epitope-tagged PDE4BI-Y358C and WT constructs expressed in HEK-293 cells (paired-t(5)=2.90, $p<0.05$ ). (d) No PDE4BI expression differences in hippocampus or amygdala. PDE4B $358 \mathrm{C} / \mathrm{Y}_{358 \mathrm{C}}$ mice have increased expression of DISCI and $\beta$-arrestin I,2 specific to the hippocampus ( $\beta$-Arrestin I,2 $t(6)=2.66, p<0.05 ; \mathrm{DISCl} t(6)=5.06, p<0.0 \mathrm{I})$ and amygdala $(\beta$-Arrestin I,2 $t(14)=2.94, p<0.05$; DISCI $t(6)=6.56, p<0.00 I)$. (e) Increased phosphorylation of CREB in the PDE4B ${ }^{Y 358 C / Y 358 C}$ hippocampus $(t(6)=5.17, p<0.0 \mathrm{I})$ and amygdala $(t(6)=2.89, p<0.05)$. (f) Lower DISCI immunoprecipitation in HEK-293 cells expressing VSV-epitope-tagged Y358C PDE4BI $(t(4)=2.90, p<0.05)$. (g) Whole brain co-immunoprecipitation demonstrating impaired PDE4BI-DISCI binding in PDE4B $358 \mathrm{C} / 358 \mathrm{C}$ mice $(t(9)=3.74, p<0.0 \mathrm{I})$. (h) Increased DISCI $(t(4)=4.48, p<0.05)$ but not $\beta$-Arrestin I,2 (t(4)=1.39, NS) expression in HEK-293 cells expressing VSV-epitopetagged PDE4BI-Y358C constructs. Means \pm SEM in all graphs, $* p<0.05, * * p<0.01$, $* * * *<0.001$. cAMP, cyclic adenosine monophosphate; DISCI, Disrupted in Schizophrenia I; NS, not significant. 
a

Elevated Plus Maze
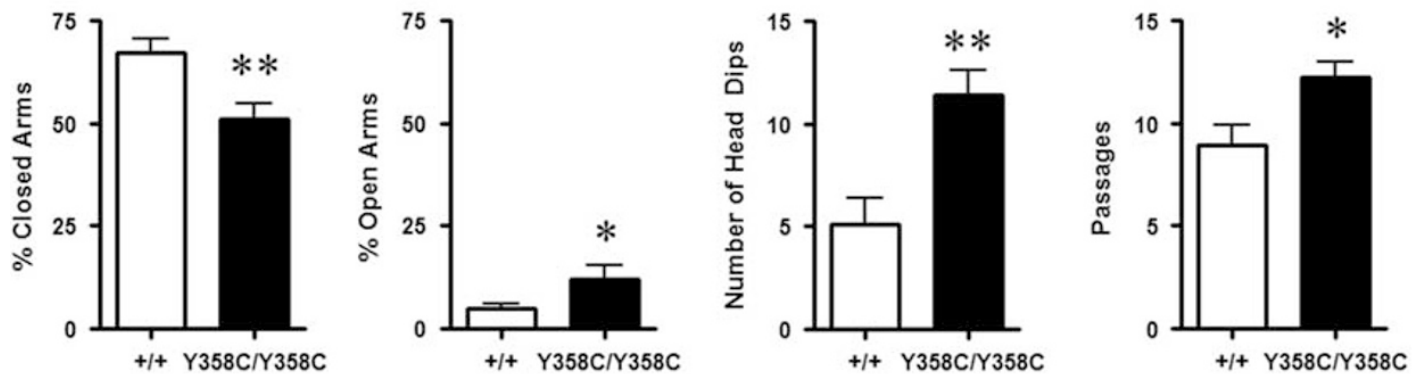

b

Open Field
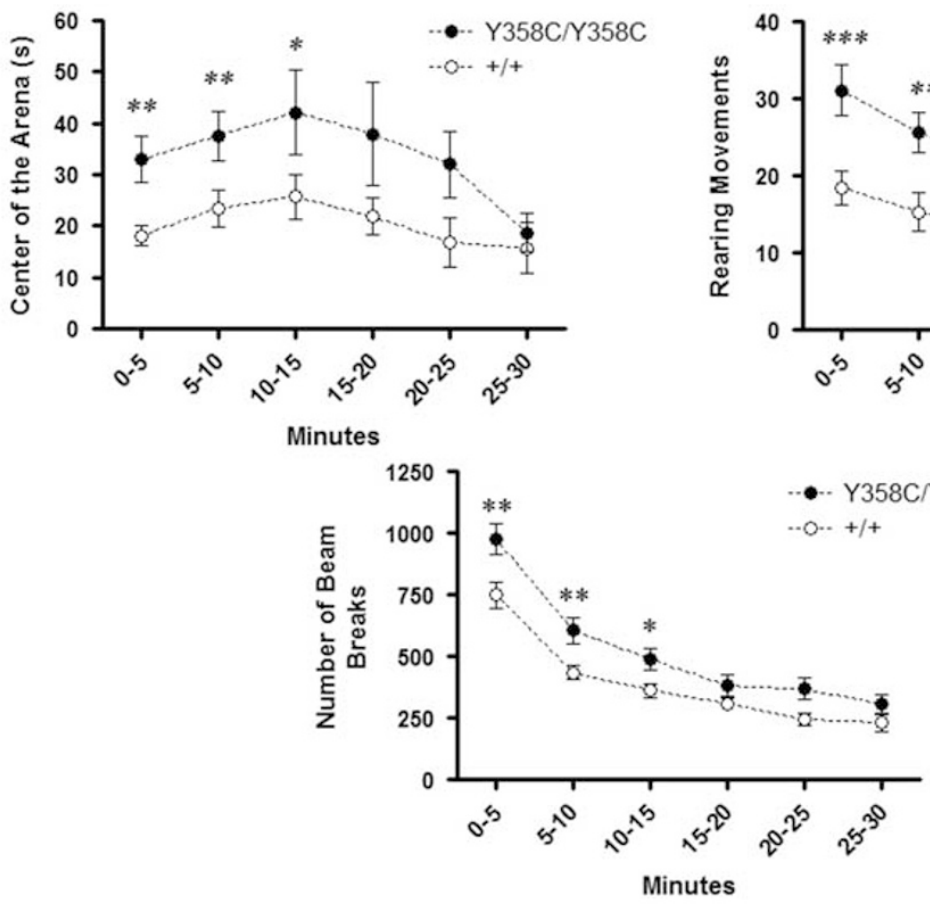

C Light-Dark Box

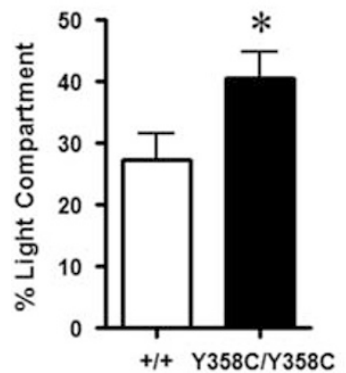

d
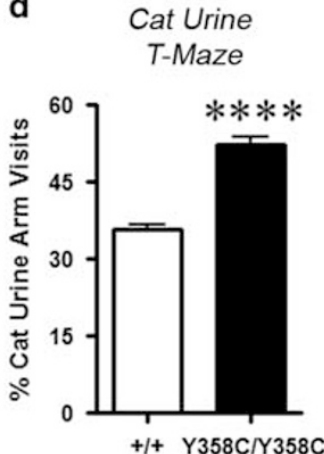

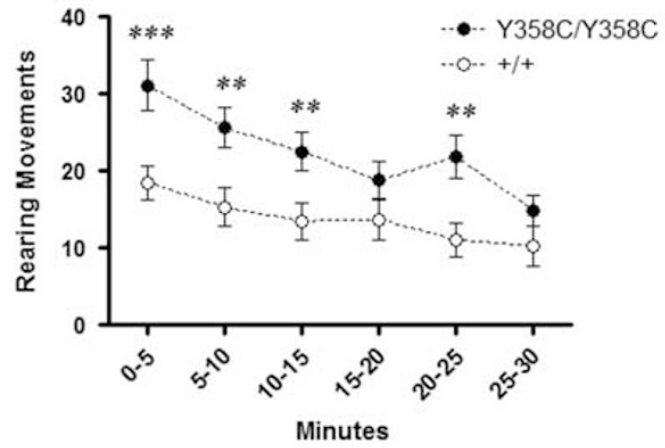

Minutes e Hole Board

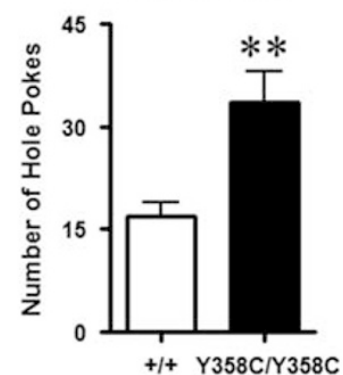

f

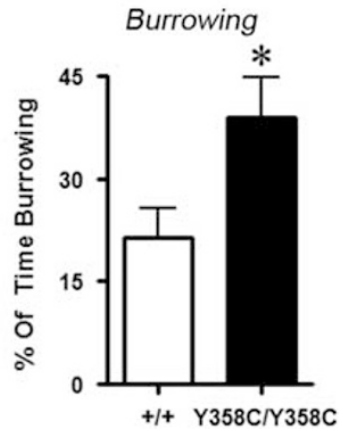

Figure 2 Anxiety and exploration. (a) Elevated plus maze. PDE4B ${ }^{Y 358 C / Y 358 C}$ mice $(n=9 \mathrm{M} / 6 \mathrm{~F})$ spent less time than PDE4B ${ }^{+/+}(n=10 M / 5 F)$ in the closed arms $(t(28)=3.28, p<0.0 \mathrm{I})$, more time in the open arms $(t(28)=2.09, p<0.05)$, performed more head dips $(t(28)=3.66, p<0.0 \mathrm{I})$ and more passages between arms $(t(28)=2.59, p<0.05)$. (b) Open-field. PDE4B $358 \mathrm{C} / 358 \mathrm{C}$ mice $(n=13 \mathrm{M} / 8 \mathrm{~F})$ spent more time than PDE4B ${ }^{+/+}(n=12 \mathrm{M} / 9 \mathrm{~F})$ in the centre of the arena $($ Time $F(5,200)=4.43, p<0.00 \mathrm{I}$; Genotype $F(I, 200)=5.0 \mathrm{I}, p<0.05$; Time $\times$ Genotype $F(I, 200)=0.84$, NS), more rearing movements (Time $F(5$, $200)=21.83, p<0.0001$; Genotype $F(I, 200)=7.30, p<0.01$; Time $\times$ Genotype $F(I, 200)=3.28, p<0.01$ ), and more total beam breaks $(G e n o t y p e: F(I$, $200)=8.06, p<0.0$ I); Time: $F(5,200)=127.1, p \leq 0.000$ I; Genotype $\times$ Time: $F(5,200)=2.32, p<0.05)$. (c) Light-dark box. PDE4B ${ }^{Y 358 C / Y 358 C}(n=6 M / 5 F)$ mice spent more time than PDE4B ${ }^{+/+}(n=7 \mathrm{M} / 5 \mathrm{~F})$ in the light compartment $(\mathrm{t}(2 \mathrm{I})=2.16, p<0.05)$. (d) Aversion to cat odor. PDE4B ${ }^{+/+}(n=5 \mathrm{M} / 3 \mathrm{~F})$ mice avoided the bobcat urine baited arm whereas PDE4B ${ }^{358 C / 358 C}(n=5 \mathrm{M} / 5 \mathrm{~F})$ visited the both arms equally $(t(I 6)=8.7 \mathrm{I}, p<0.000 \mathrm{I})$. (e) Holeboard.

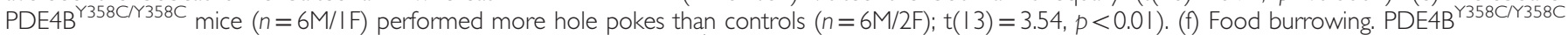
mice $(n=5 \mathrm{M} / 5 \mathrm{~F})$ spent significantly more time foraging than PDE4B ${ }^{+/+}(n=5 \mathrm{M} / 5 \mathrm{~F} ; t(18)=2.42, p<0.05)$. Means $\pm \mathrm{SEM}$ in all graphs, * $p<0.05, * * *<<0.01$, ***** $p<0.00$ I. F, female; M, male; NS, not significant. 
mice (Figure 1d). The DISC1 upregulation was confirmed using VSV-epitope-tagged human PDE4B1-Y358C and WT constructs expressed in HEK-293 cells (Figure 1h). $\beta$-Arrestins are known to recruit PDE4 to the $\beta 2$-adrenoreceptor, thus controlling PKA activity at the membrane (Baillie et al, 2003; Li et al, 2011b). Though PDE4B1- $\beta$-Arrestin $1 / 2$ binding was not impaired in $\mathrm{PDE} 4 \mathrm{~B}^{\mathrm{Y} 358 \mathrm{C} / \mathrm{Y} 358 \mathrm{C}}$ mice (Supplementary Figure 2f), $\beta$-Arrestin $1 / 2$ was increased 1.6 -fold in the hippocampus and 1.3-fold in the amygdala (Figure 1d), but not in prefrontal cortex and nucleus accumbens (Supplementary Figure 2b and c).

\section{PDE4B Y358C Mice Display Decreased Anxiety and Greater Exploratory Behavior}

In the elevated plus maze, mice face a conflict between aversion to open arms and motivation to explore these arms. $\mathrm{PDE} 4 \mathrm{~B}^{\mathrm{Y} 358 \mathrm{C} / \mathrm{Y} 358 \mathrm{C}}$ mice spent more time in the open arms and made more exploratory head dips and passages than $\mathrm{PDE}_{4} \mathrm{~B}^{+/+}$ mice (Figure $2 \mathrm{a}$ ). In a novel open field, PDE4B ${ }^{\mathrm{Y} 358 \mathrm{C} / \mathrm{Y} 358 \mathrm{C}}$ mice displayed greater ambulation and rearing activity, and spent more time in the aversive center of the arena (Figure 2b). Further, PDE4B ${ }^{\mathrm{Y} 358 \mathrm{C} / \mathrm{Y} 358 \mathrm{C}}$ mice spent more time in the bright compartment of the light-dark box (Figure 2c). We exploited murine aversion to cat odors (Vyas et al, 2007) by baiting a T-maze with food pellets in one arm and bobcat urine in the opposite arm. PDE4B ${ }^{+/+}$mice avoided the bobcat urine arm, whereas $\mathrm{PDE} 4 \mathrm{~B}^{\mathrm{Y} 358 \mathrm{C} / \mathrm{Y} 358 \mathrm{C}}$ mice explored both arms equally (Figure 2d). This difference was not attributable to impaired olfaction (Supplementary Figure 3a).

In a holeboard test of exploratory behavior, PDE4B ${ }^{\mathrm{Y} 358 \mathrm{C} / \mathrm{Y} 358 \mathrm{C}}$ mice performed more nose-pokes than $\mathrm{PDE}_{4} \mathrm{~B}^{+/+}$mice (Figure 2e). When attempting to find buried food, PDE4B ${ }^{\mathrm{Y} 358 \mathrm{C} / \mathrm{Y} 358 \mathrm{C}}$ mice engaged in greater exploratory burrowing than $\mathrm{PDE}_{4} \mathrm{~B}^{+/+}$mice (Figure 2f). This was not merely hyperlocomotion (Supplementary Figure $3 \mathrm{~b}$ ). $\mathrm{PDE} 4 \mathrm{~B}^{\mathrm{Y} 358 \mathrm{C} / \mathrm{Y} 358 \mathrm{C}}$ mice thus exhibited a consistent pattern of lower anxiety, and greater exploratory behavior and risk-taking.

We did not observe differences in depressive-like behavior using the forced swim test (Supplementary Figure 3b).

\section{PDE4B Y358C Mice Display Enhanced Learning and Memory}

In the $\mathrm{Y}$-maze spontaneous alternation test, $\mathrm{PDE} 4 \mathrm{~B}^{\mathrm{Y} 358 \mathrm{C} / \mathrm{Y} 358 \mathrm{C}}$ mice exhibited improvements in working spatial memory (Figure 3a). In the Morris water maze, PDE4B ${ }^{\mathrm{Y} 358 \mathrm{C} / \mathrm{Y} 358 \mathrm{C}}$ mice located the escape platform faster than $\mathrm{PDE}_{4} \mathrm{~B}^{+/+}$mice in both acquisition and reversal training trials (Figure 3b), an effect not attributable to swimming time or speed (Supplementary Figure $3 \mathrm{~b}$ and c). Moreover, PDE4B ${ }^{\mathrm{Y} 358 \mathrm{C} / \mathrm{358C}}$ mice had improved performance compared to $\mathrm{PDE}_{4} \mathrm{~B}^{+/+}$mice in probe trials $24 \mathrm{~h}$ after the last acquisition and reversal trials (Figure 3b). In a social recognition test, $\mathrm{PDE} 4 \mathrm{~B}^{\mathrm{Y} 358 \mathrm{C} / \mathrm{Y} 358 \mathrm{C}}$ mice demonstrated enhanced long-term (24h) memory of a familiar juvenile compared with PDE4B ${ }^{+/+}$mice (Figure $3 \mathrm{c}$ ).

Object location recognition is a hippocampus-dependent task exploiting the natural exploratory activity of rodents toward spatial novelty to assess the detection of spatial relocation of a known object (Stupien et al, 2003).
$\mathrm{PDE} 4 \mathrm{~B}^{\mathrm{Y} 358 \mathrm{C} / \mathrm{Y} 358 \mathrm{C}}$ and $\mathrm{PDE} 4 \mathrm{~B}^{+/+}$mice displayed similar preferences for displaced objects following a 10-min acquisition period, but only $\mathrm{PDE} 4 \mathrm{~B}^{\mathrm{Y} 358 \mathrm{C} / \mathrm{Y} 358 \mathrm{C}}$ mice demonstrated a preference for displaced objects when the acquisition period was reduced to $5 \mathrm{~min}$ (Figure $3 \mathrm{~d}$ ). We have previously shown that decreasing environmental threat by dimming the lights results in increased exploration with consequent improvement in memory (Saab et al, 2009). As $\mathrm{PDE} 4 \mathrm{~B}^{\mathrm{Y} 358 \mathrm{C} / \mathrm{Y} 358 \mathrm{C}}$ mice already display increased exploratory behavior under typical room lighting ('bright lights'; Figure 2), we sought to increase the environmental threat by exposing mice to brighter lights and a transparent arena floor at $1-\mathrm{m}$ elevation. In this more aversive environment, $\mathrm{PDE}_{4} \mathrm{~B}^{+/+}$mice failed to show preference for displaced objects following $10 \mathrm{~min}$ of acquisition, but the displaced object preference of PDE4B ${ }^{\mathrm{Y} 358 \mathrm{C} / \mathrm{Y} 358 \mathrm{C}}$ mice was maintained, even when acquisition was limited to 5 min (Figure $3 \mathrm{~d}$ ).

\section{PDE4B Y358C Mice Display Altered Fear Memory}

In the fear conditioning paradigm, $\mathrm{PDE} 4 \mathrm{~B}^{\mathrm{Y} 358 \mathrm{C} / \mathrm{Y} 358 \mathrm{C}}$ mice demonstrated levels of freezing comparable with $\mathrm{PDE}_{4 \mathrm{~B}}{ }^{+/+}$ mice in the hippocampus-dependent contextual memory test $24 \mathrm{~h}$ after conditioning, but showed decreased freezing in the amygdala-dependent cued memory test (Figure $3 \mathrm{e}$ ). When a portion of this cohort was retested 7 days after conditioning, $\mathrm{PDE} 4 \mathrm{~B}^{\mathrm{Y} 358 \mathrm{C} / \mathrm{Y} 358 \mathrm{C}}$ mice displayed less freezing to the context than $\mathrm{PDE} 4 \mathrm{~B}^{+/+}$mice (Supplementary Figure $4 \mathrm{a}$ ). Therefore, 7-day fear memory was tested in an independent cohort, in which PDE4B ${ }^{\mathrm{Y} 358 \mathrm{C} / \mathrm{Y} 358 \mathrm{C}}$ mice showed lower levels of both contextual freezing and cued freezing after 7 days, in the absence of exposure at $24 \mathrm{~h}$ (Figure 3f). The $\mathrm{PDE} 4 \mathrm{~B}^{\mathrm{Y} 358 \mathrm{C} / \mathrm{Y} 358 \mathrm{C}}$ decreased freezing is not attributable to altered nociception, or to sensorimotor processing as assessed using the prepulse inhibition test (Supplementary Figure $4 b-d)$.

To further examine the effect of PDE4B functional impairment on 7-day fear memory, twice daily injections of the nonselective PDE4 inhibitor rolipram $(1 \mathrm{mg} / \mathrm{kg})$ were administered to $\mathrm{PDE} 4 \mathrm{~B}^{+/+}$mice from $24 \mathrm{~h}$ to 6 days after conditioning. Compared with vehicle-treated controls, the rolipram-treated mice exhibited a contextual memory-specific reduction in freezing (Figure 3g), supporting our PDE4B ${ }^{\mathrm{Y} 358 \mathrm{C} / \mathrm{Y} 358 \mathrm{C}}$ findings.

\section{PDE4B Y358C Mice Display Altered Synaptic Plasticity}

Hippocampal CA1 electrophysiological experiments were used to explore synaptic plasticity in PDE4B ${ }^{\mathrm{Y} 358 \mathrm{C} / \mathrm{Y} 358 \mathrm{C}}$ mice. The Y358C mutation did not affect basal synaptic transmission (Supplementary Figure 5). We applied forskolin, an adenylyl cyclase activator, and found increased potentiation in $\mathrm{PDE} 4 \mathrm{~B}^{\mathrm{Y} 358 \mathrm{C} / \mathrm{Y} 358 \mathrm{C}}$ hippocampal slices, confirming decreased PDE4B-Y358C cAMP hydrolytic function (Figure 4a). To examine the effect of sustained electrical stimulation on LTP in PDE4B ${ }^{\mathrm{Y} 358 \mathrm{C} / \mathrm{Y} 358 \mathrm{C}}$ mice, we utilized high frequency $(100-\mathrm{Hz})$ trains and varied their number. Following tetanic stimulation with four trains, PDE4B ${ }^{\mathrm{Y} 358 \mathrm{C} / \mathrm{Y} 358 \mathrm{C}}$ slices demonstrated enhanced potentiation (Figure $4 \mathrm{~b}$ ). Given the rapid acquisition observed in object recognition (Figure 3d), we employed a single $100-\mathrm{Hz}$ train, which is below the typical threshold for LTP (Albensi et al, 2007). PDE4B ${ }^{\mathrm{Y} 358 \mathrm{C} / \mathrm{Y} 358 \mathrm{C}}$ slices showed evidence of 
a

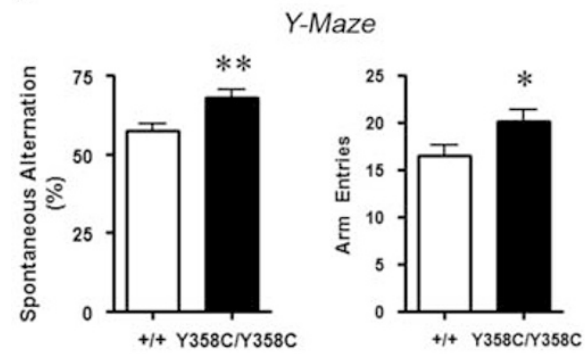

b

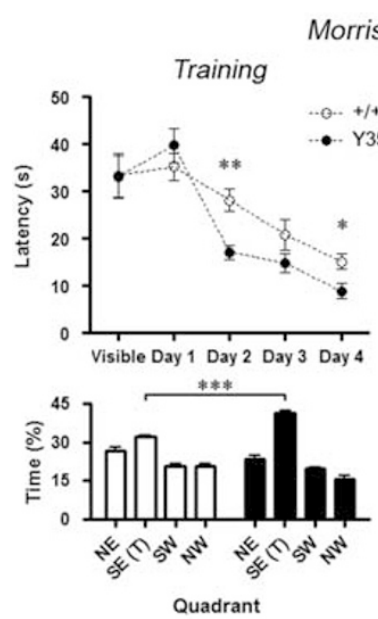

Morris Water Maze

e

Fear Conditioning - 24 hours
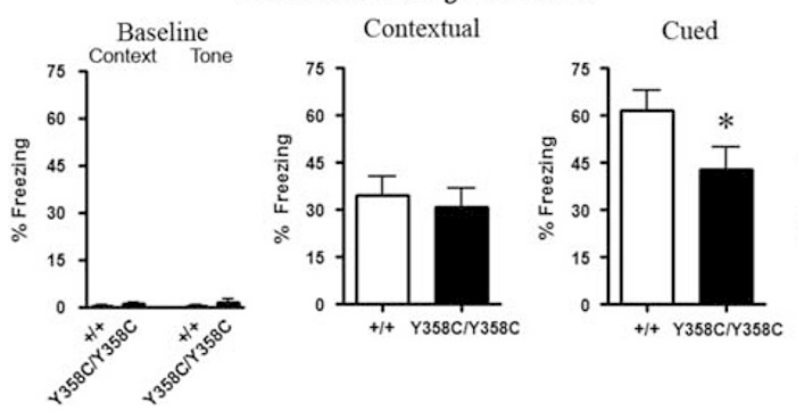

g

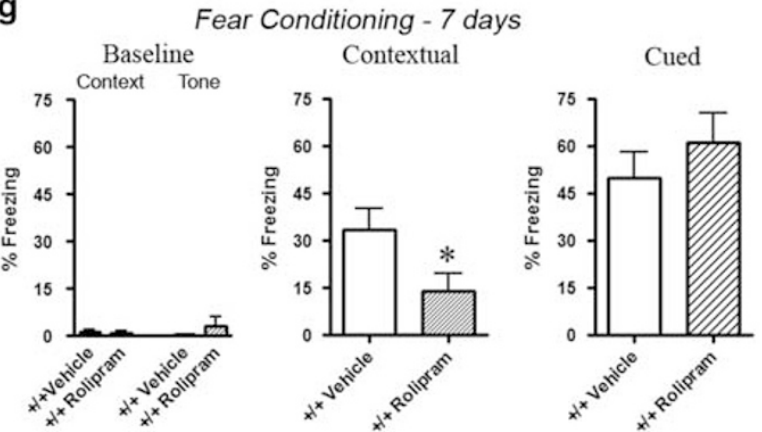

C

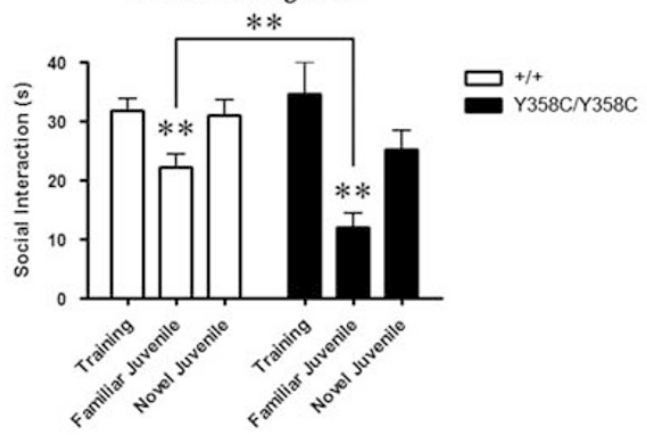

d

Object Location Recognition
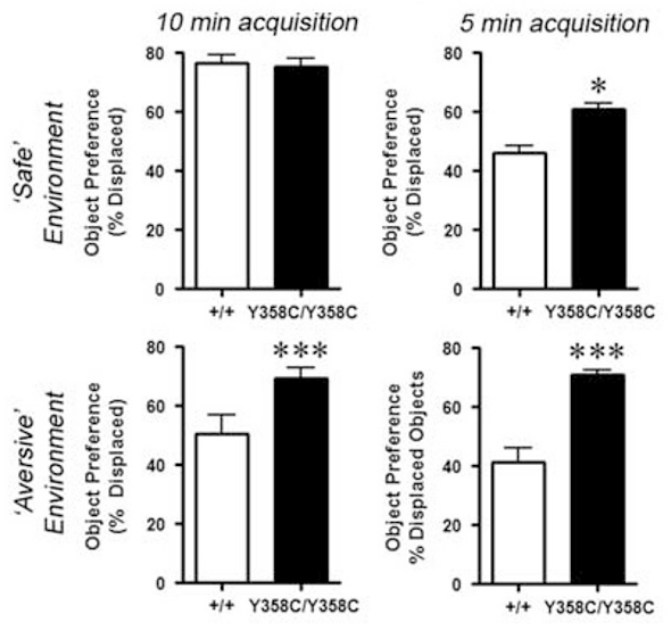

f

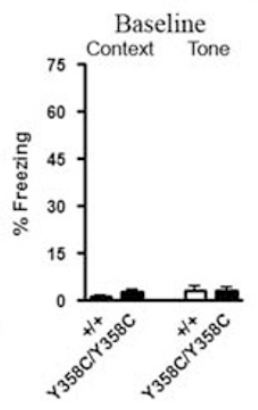

Fear Conditioning - 7 days
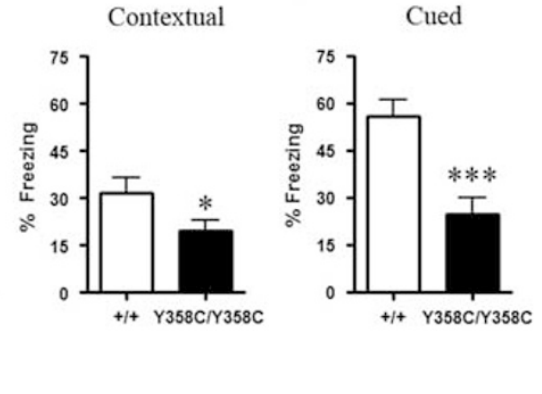

facilitation, whereas PDE4B ${ }^{+/+}$slices, as expected, demonstrated non-significant potentiation (Figure $4 \mathrm{c}$ ). We examined synaptic depression in PDE4B ${ }^{\mathrm{Y} 358 \mathrm{C} / \mathrm{Y} 358 \mathrm{C}}$ mice, but observed no change in slices from 16-17-day-old mice after 900 pulses of $1-\mathrm{Hz}$ stimulation (Figure $4 \mathrm{~d}$ ). As our behavioral studies were conducted on 8-12 week old mice, we also studied an adult form of synaptic depression-depotentiation-whereby tetanic stimulation is followed by low frequency stimulation 
(Grunwald et al, 2001). Depotentiation restored fEPSP slopes to baseline in $\mathrm{PDE} 4 \mathrm{~B}^{+/+}$slices but resulted in less synaptic depression in $\mathrm{PDE} 4 \mathrm{~B}^{\mathrm{Y} 358 \mathrm{C} / \mathrm{Y} 358 \mathrm{C}}$ slices (Figure 4e). Pairedpulse facilitation showed no evidence that Y358C impaired presynaptic short-term plasticity (Figure $4 \mathrm{f}$ ).

\section{PDE4B Y358C Mice Display Increased Dendritic Spine Density and Hippocampal Neurogenesis}

The combined administration of rolipram and antidepressants to rodents results in increased BDNF expression (Fujimaki et al, 2000) and CA1 spine density (Marchetti et al, 2010). In mouse models of Alzheimer's disease, rolipram restores dendritic spine density (Smith et al, 2009), while Disc1 mutant mice with impaired DISC1-PDE4B binding show alterations in hippocampal spine density (Lee et al, 2011). We therefore sought to examine dendritic spine density in $\mathrm{PDE} 4 \mathrm{~B}^{\mathrm{Y} 358 \mathrm{C} / \mathrm{Y} 358 \mathrm{C}}$ mice, focusing on the hippocampus and lateral amygdala. Using the Thy1-GFP transgene (Feng et al, 2000) as a reporter for dendritic spines, we identified greater spine densities in both the hippocampus and lateral amygdala of PDE $4 \mathrm{~B}^{\mathrm{Y} 358 \mathrm{C} / \mathrm{Y} 358 \mathrm{C}}$ mice (Figure 5a).
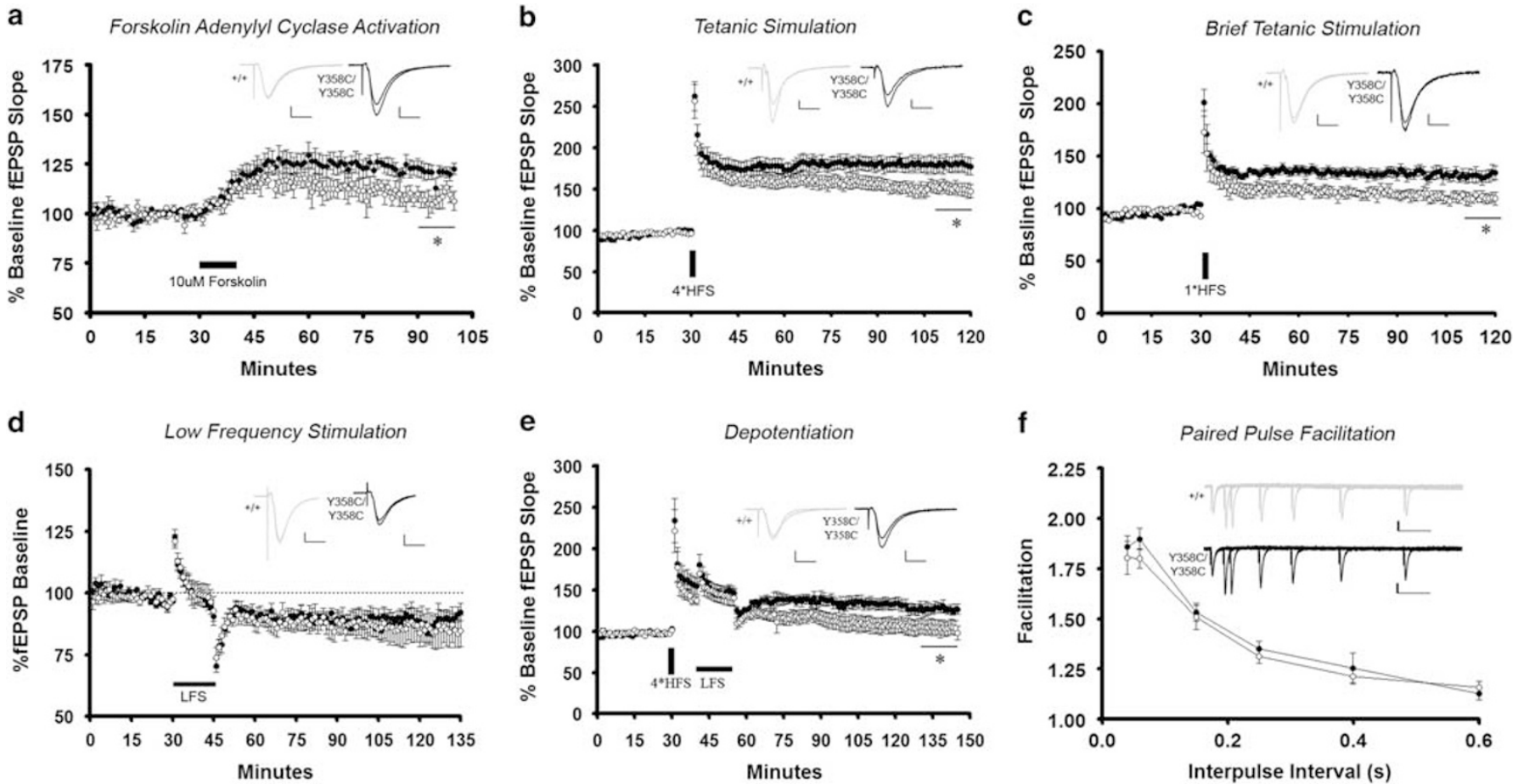

Figure 4 Synaptic plasticity in Schaffer collaterals of hippocampal CAI neurons. (a) Enhanced potentiation after forskolin challenge in PDE4B ${ }^{\text {3358C/Y358C }}$ slices $\left(t(7)=2.62, p<0.05\right.$; PDE4B ${ }^{Y 358 C / Y 358 C}$ four slices from three mice; PDE4B ${ }^{+/+}$five slices from three mice). (b) Facilitated and stable LTP upon tetanic stimulation in PDE4B ${ }^{Y 358 C / Y 358 C}$ slices $\left(t(18)=2.36, p<0.05\right.$; PDE4B ${ }^{Y 358 C} / Y_{358 C}$ I I slices from 10 mice, PDE4B ${ }^{+/+}$I 0 slices from 6 mice). (c) Facilitated and stable LTP from

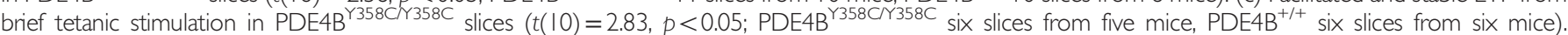
(d) Low-frequency stimulation results in comparable LTD (PDE4B ${ }^{Y 358 C / 3358 C}$ six slices from three mice, PDE4B ${ }^{+/+}$six slices from three mice). (e) Impaired depotentiation in PDE4B ${ }^{Y 358 C / 358 C}$ mice (PDE4B ${ }^{Y 358 C / Y 358 C}$ seven slices from seven mice, PDE4B ${ }^{+/+}$nine slices from nine mice). (f) Y358C mutation does not affect pre-synaptic short-term plasticity. Representative fEPSPs are presented for each experiment (PDE4B ${ }^{+/+}$gray, PDE4B ${ }^{\text {Y358C/Y } 358 C}$ black). For panels a- $d$ the scale represents $10 \mathrm{~ms}$ and $0.2 \mathrm{mV}$, and $100 \mathrm{~ms}$ and $0.2 \mathrm{mV}$ in panel $\mathrm{f}$. Means \pm SEM in all graphs, ${ }^{*} p<0.05$. LTP, long-term potentiation.

Figure 3 Cognitive enhancement and fear memory. (a) Y-maze. PDE4B ${ }^{Y 358 C / Y 358 C}$ mice $(n=|||M / I| F)$ demonstrated improved working memory with more spontaneous alternation $(n=10 M / I 7 F ; t(47)=3.02, p<0.01)$ and increased arm entry $(t(47)=2.27, p<0.05)$ than PDE4B ${ }^{+/+}$. (b) Morris water maze. PDE4B ${ }^{358 C / Y 358 C}$ mice $(n=4 M / 4 F)$ demonstrated more rapid spatial memory acquisition than $\mathrm{PDE}^{3} \mathrm{~B}^{+/+}(n=6 \mathrm{M} / 3 \mathrm{~F})$ during the training $(\mathrm{Genotype}$ $F(I, 45)=2.27, p=0.059)$; Genotype $\times$ Time $F(3,45)=4.6 I, p<0.0 I$ ) and reversal learning (Genotype $F(I, 30)=8.80, p<0.0 I ; G e n o t y p e \times D a y \quad F$ $(2,30)=3.73, p<0.05)$ phases. PDE4B ${ }^{Y 358 C / Y 358 C}$ mice spent more time in the target quadrant on the probe trial after training $(Q$ uadrant $F(3,60)=133.6$, $p<0.0001$; Genotype $\times$ Quadrant $F(3,60)=20.31, p<0.000 I$ ) and after reversal learning (Quadrant $F(3,32)=110.6$, $p<0.000 I$; Genotype $\times$ Quadrant $F(3,32)=21.22, p<0.000 I)$. (c) Social recognition. PDE4B ${ }^{Y 358 C / Y 358 C}$ mice exhibit improved social memory $(Y 358 \mathrm{C} n=7 M$ vs $W T n=9 M ; t(I 4)=3.13$, $p<0.0$ I). (d) Displaced object location recognition. Ten-minute acquisition in 'safe' environment (top left) reveals comparable displaced object preference between genotypes. Five-minute acquisition in a 'safe' environment (top right; Y358C IOM/2F vs WT I0M/2F; $t(22)=4.58, p<0.000$ I), 5-min acquisition in a 'aversive' environment (bottom right; $t(13)=6.64, p<0.000 \mathrm{I}$ ), and I0-min acquisition in an 'aversive' environment (bottom left; $t(14)=2.60, p<0.05)$ all reveal greater displaced object preference in PDE4B ${ }^{Y 358 C / Y 358 C}$ mice. (e) Fear conditioning - $24 \mathrm{~h}$. PDE4B ${ }^{Y 358 C / Y 358 \mathrm{C}}$ mice $(n=7 M / 5 \mathrm{~F})$ exhibit normal contextual and decreased cued freezing compared to PDE4B ${ }^{+/+}(n=6 \mathrm{M} / 6 \mathrm{~F}) 24 \mathrm{~h}$ after fear conditioning $(t(22)=1.99, p<0.05)$. ( $\left.f\right)$ Fear conditioning-7 days. PDE4B ${ }^{Y 358 C / Y 358 C}(n=7 M / 6 F)$ mice exhibit decreased contextual $(t(25)=2.08, p<0.05)$ and decreased cued $(t(25)=4.08, p<0.00 \mathrm{I})$ freezing compared to

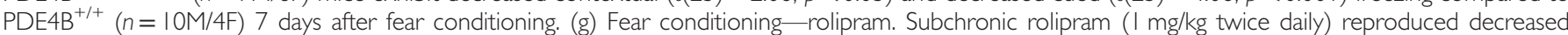
contextual freezing 7 days after training in $+/+$ mice (rolipram $n=8 M / I F$ vs vehicle $n=7 M / I F ; t(I 5)=2.27, p<0.05$ ). Means $\pm S E M$ in all graphs, * $p<0.05$, *** $p<0.0$ I, **** $p<0.001$. F, female; M, male; NS, not significant; WT, wild type. 

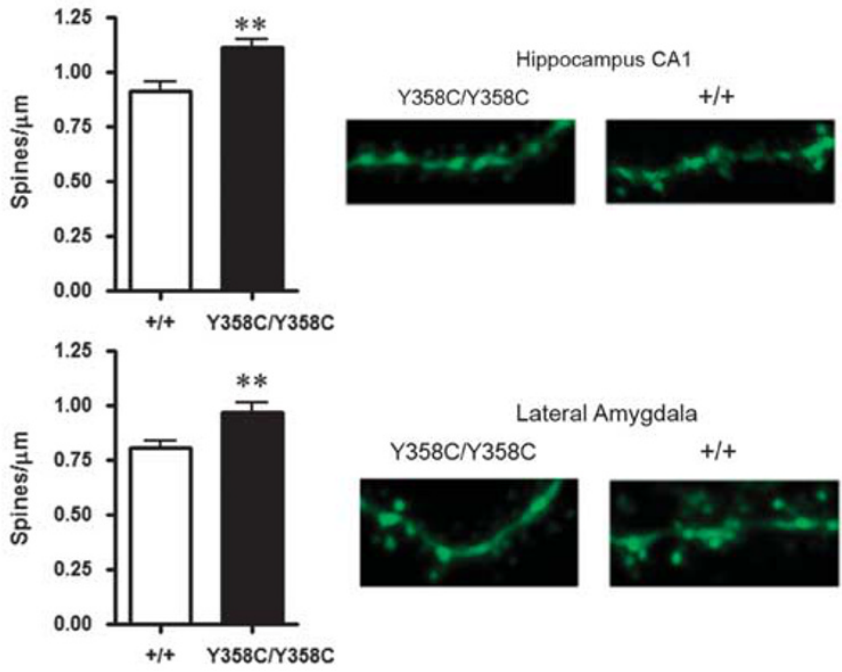

b

Doublecortin

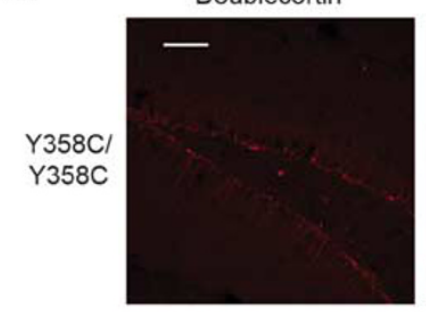

$\mathrm{Y} 358 \mathrm{C} /$ Y358C
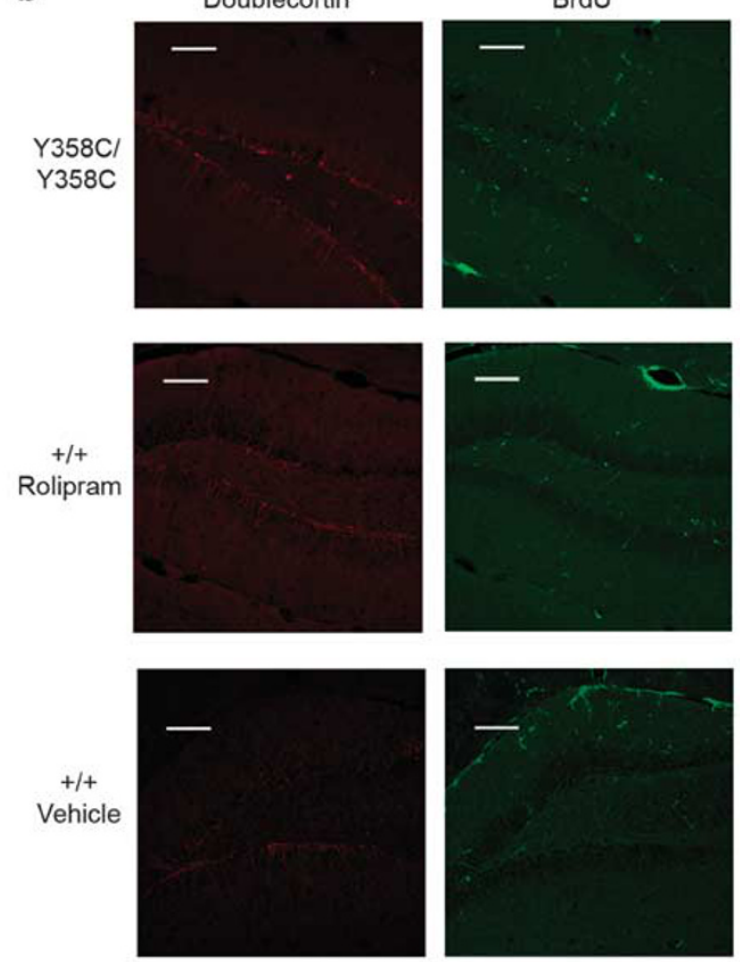

Y $358 \mathrm{C} / \mathrm{Y} 358 \mathrm{C}$
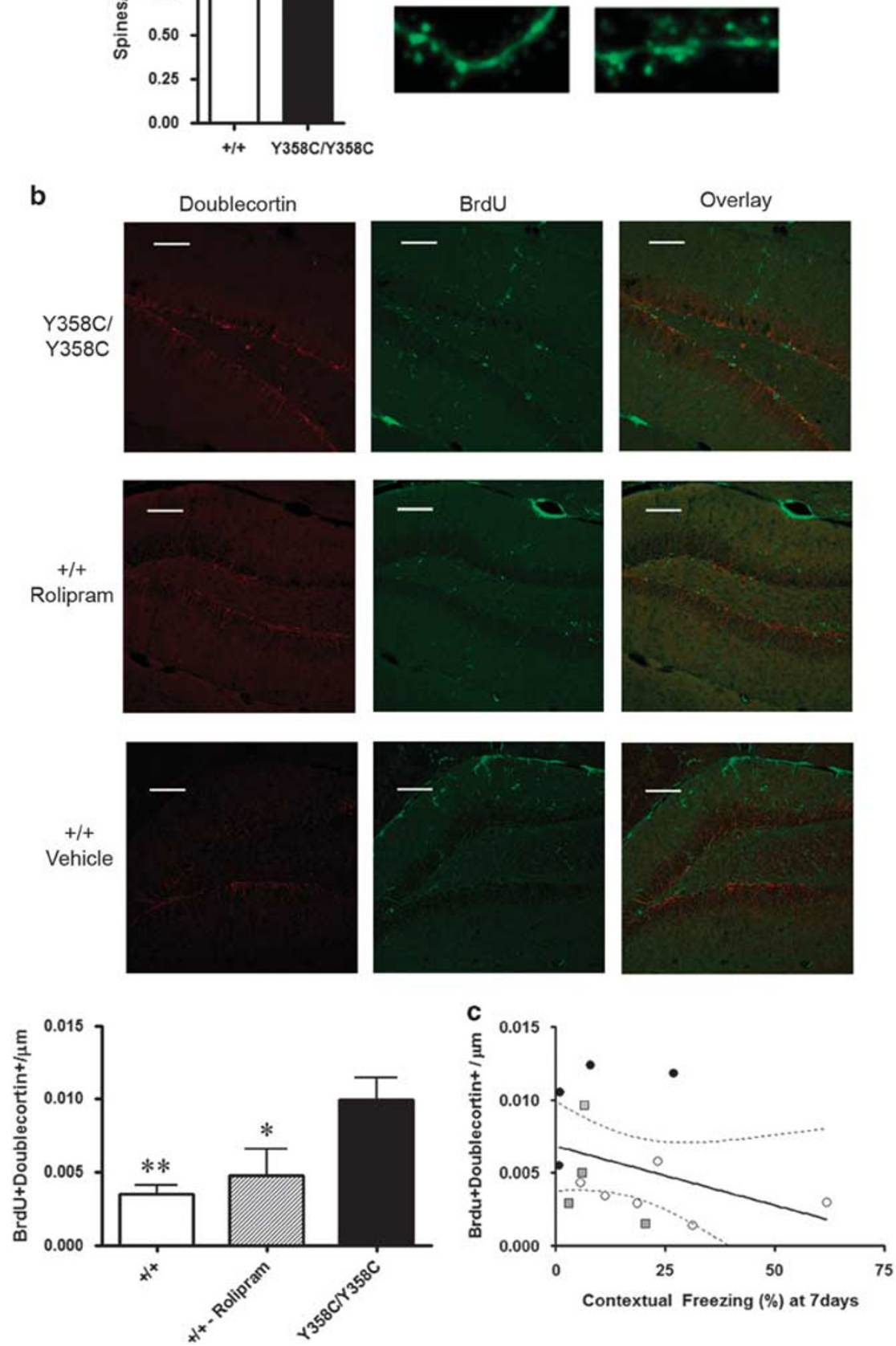

Figure 5 Dendritic spine density and neurogenesis. (a) Increased dendritic spine density in both the hippocampus (34 segments from 4 Thy l-GFP mice; $t(32)=3.57, p<0.0 I$ ) and the amygdala (43 segments from 4 Thyl-GFP mice; $t(4 \mathrm{I})=3.0 \mathrm{I}, p<0.0 \mathrm{I}$ ) of PDE4B ${ }^{Y 358 C / Y 358 \mathrm{C}}$ mice. (b) Increased dentate neurogenesis among PDE4B ${ }^{Y 358 C / 338 C}$ mice compared with control mice receiving rolipram I $\mathrm{mg} / \mathrm{kg}$ or vehicle twice daily for 6 days $(F(2,12)=8.80$, $p<0.0 \mathrm{I}$ ). (c) Subgranual layer neurogenesis was not related to contextual freezing 7 days after fear conditioning $(F(I, I 3)=2.0 I, N S)$. * $p<0.05, * * p<0.01$. GFP, green fluorescent protein; NS, not significant. 
Enhanced adult hippocampal neurogenesis has been observed in both $P d e 4 b$ and Pde4d KO mice (Li et al, 2011b; Zhang et al, 2008). In light of data indicating that adult hippocampal dentate neurogenesis destabilizes contextual fear memory (Akers et al, 2014), we probed neurogenesis in conjunction with fear conditioning. Using daily injections of 5-bromo-2'-deoxyuridine (BrdU; $50 \mathrm{mg}$ / $\mathrm{kg}$, i.p.) for four days following fear conditioning, we examined neurogenesis in the hippocampal dentate gyrus of $\mathrm{PDE} 4 \mathrm{~B}^{\mathrm{Y} 358 \mathrm{C} / \mathrm{Y} 358 \mathrm{C}}$ mice in comparison with $\mathrm{PDE}_{4} \mathrm{~B}^{+/+}$ mice that received rolipram $(1 \mathrm{mg} / \mathrm{kg})$ or vehicle twice daily for 6 days. Increased numbers of dentate BrdU+ and doublecortin+ cells were observed in PDE4B ${ }^{\mathrm{Y} 358 \mathrm{C} / \mathrm{Y} 358 \mathrm{C}}$ mice compared with both rolipram-treated and vehicle-treated $\mathrm{PDE}_{4} \mathrm{~B}^{+/+}$mice (Figure 5b). However, no significant relationship was observed between adult hippocampal neurogenesis and contextual freezing with linear regression (Figure 5c).

\section{DISCUSSION}

The present study sought to determine the neural and behavioral effects of a catalytic domain mutant form of PDE4B (Y358C) that has decreased ability to hydrolyze cAMP. Consistent with previous data suggesting the involvement of the Y358 residue in the interaction of PDE4B with DISC1 (Murdoch et al, 2007), our comparative molecular modeling suggested that the cysteine substitution resulted in a conformational modification rendering the DISC1 interaction site inaccessible. Confirmed in cell culture and brain tissue, the decreased binding of PDE4B-Y358C to DISC1 was associated with increased expression of DISC1 and $\beta$ arrestin $1 / 2$ in the amygdala and hippocampus, perhaps indicating compensatory mechanisms to normalize PDE4B activity. Moreover, our modeling suggested impaired cAMP binding owing to tertiary changes as a result of the Y358C substitution. Indeed, $27 \%$ impairment in cAMP hydrolytic ability of PDE4B1-Y358C observed in vitro is proportional to that of physiological regulation by phosphorylated ERK (Baillie et al, 2000). The importance of the Y358C alteration was confirmed ex vivo in forskolin-challenged hippocampal slices, which demonstrated rapid cAMP accumulation and sustained potentiation at Schaffer CA1 collaterals.

$\mathrm{PDE} 4 \mathrm{~B}^{\mathrm{Y} 358 \mathrm{C} / \mathrm{Y} 358 \mathrm{C}}$ mice consistently demonstrated low levels of anxiety in several tests, and even failed to demonstrate the natural robust innate fear response to cat odor. A decreased fear response to cat odor is also shown by mice infected with Toxoplasma gondii (Vyas et al, 2007), a schizophrenia risk factor that localizes to the lateral amygdala involved in both innate and learned fear (LeDoux, 2000). Pde $4 b \mathrm{KO}$ mice show anxiogenic-like behaviour in the holeboard and light-dark transition tests (Zhang et al, 2008), and therefore null mutation (KO) and missense mutation (Y358C) of Pde4b appear to have opposite effects on some tests of anxiety (Rutten et al, 2011; Siuciak et al, 2008; Zhang et al, 2008). Such phenotypic differences between mice which harbor a missense mutation or null mutation (KO) of the same gene are not uncommon; for example, missense mutation I810N (Kirshenbaum et al, 2013) and KO (Ikeda et $a l, 2013$ ) alleles of the $\mathrm{Na}^{+}, \mathrm{K}^{+}$-ATPase $\alpha 3$ gene are reported to have opposite effects on the beam walking assay.
Our finding that reduced-function of PDE4B by a catalytic domain mutation results in anxiolytic effects is consistent with anxiolysis observed with non-selective PDE4 inhibitors in rodents (Li et al, 2009b; Silvestre et al, 1999) and primates (Rutter et al, 2014). Altogether these data suggest that the anxiolytic effects of non-selective PDE4 inhibitors may be PDE4B dependent.

In humans and mice, exploratory tendencies are predictive of general cognitive abilities (Matzel et al, 2006). However, an increased exploratory tendency does not equate to improvement in general cognitive performance (Light et al, 2008, 2011), perhaps suggesting a common substrate yet lack of causality between these factors. Reducing an environment's aversive characteristics can shift the motivation underlying exploration, resulting in learning facilitation (Saab et al, 2009). The PDE4B-Y358C mutation decreased fear responses and increased exploration in mice, and we observed a consistent pattern of cognitive enhancement in $\mathrm{PDE} 4 \mathrm{~B}^{\mathrm{Y} 358 \mathrm{C} / \mathrm{Y} 358 \mathrm{C}}$ mice in non-aversive tests. The resistance shown by $\mathrm{PDE} 4 \mathrm{~B}^{\mathrm{Y} 358 \mathrm{C} / \mathrm{Y} 358 \mathrm{C}}$ mice to the negative influence of environmental threat on object location memory formation suggests dissociation between fear and memory formation. Our learning and memory as well as synaptic findings are consistent with the PDE4B-Y358C mutant's reduced cAMP hydrolytic activity and facilitation of CREB phosphorylation (Tully et al, 2003).

In fear conditioning, inputs are received within the lateral amygdala to form an association between the auditory tone (conditioned stimulus) and the foot-shock (unconditioned stimulus) (LeDoux, 2000). The deficits in PDE4B ${ }^{\mathrm{Y} 358 \mathrm{C} / \mathrm{Y} 358 \mathrm{C}}$ cued memory may reflect altered lateral amygdala function, consistent with $\beta$-Arrestin upregulation and the $\beta$-Arrestin-PDE4 complex required for fear conditioning ( $\mathrm{Li}$ et al, 2009a). Yet PDE4B ${ }^{\mathrm{Y358C} / \mathrm{Y} 358 \mathrm{C}}$ mice had intact contextual (hippocampal) fear memory at $24 \mathrm{~h}$, which is considered sufficient time for the formation of long-term memories (Tully et al, 2003). Pde4b KO mice, by contrast, have shown no differences in context-dependent and cue-dependent fear memory tests at $24 \mathrm{~h}$ (Rutten et al, 2011). The decrease in contextual freezing exhibited by $\mathrm{PDE} 4 \mathrm{~B}^{\mathrm{Y} 358 \mathrm{C} / \mathrm{Y} 358 \mathrm{C}}$ mice when tested at 7 days is unlikely to represent extinction of fear memory, as lower contextual freezing after 7 days was observed independent of pre-exposure to the context at $24 \mathrm{~h}$. Our data suggest that this is due to PDE4B dysfunction rather than disrupted interaction with DISC1 because the PDE4B ${ }^{\mathrm{Y} 358 \mathrm{C} / \mathrm{Y} 358 \mathrm{C}}$ fear conditioning phenotype was replicated in control mice given subchronic rolipram, which inhibits PDE4B activity but does not affect binding to DISC1. Moreover, the replication of the phenotype when rolipram was initiated $24 \mathrm{~h}$ after fear conditioning suggests that $\mathrm{PDE} 4 \mathrm{~B}$ is involved in a very late process required for long-term memory persistence.

Impaired regulation of cAMP signaling in the hippocampus by PDE4B may impair a very late-phase of consolidation, perhaps by poor coordination of the late-phase protein transcription required for long-term memory persistence. Disruption of late-phase processes by injecting anisomycin or BDNF-antibodies into CA1 of the hippocampus $12 \mathrm{~h}$ after fear conditioning leads to a similar phenotype, with intact freezing at $48 \mathrm{~h}$ but decreased freezing after 7 days (Bekinschtein et al, 2007). Moreover, this phenotype has also been reported with antidepressants given $12 \mathrm{~h}$ after fear 
conditioning (Slipczuk et al, 2013). However, unlike the PDE4B ${ }^{\mathrm{Y} 358 \mathrm{C} / \mathrm{Y} 358 \mathrm{C}}$ phenotype, these previous studies detected no change in fear memory at 7 days if the interventions occurred at or after $24 \mathrm{~h}$ (Bekinschtein et al, 2007; Slipczuk et al, 2013).

Alternatively, the degree to which the PDE4B-Y358C function facilitates the acquisition of new associations and formation of new synapses may lead to loss of behavioral specificity over time. Moreover, neurogenesis in PDE4B ${ }^{\mathrm{Y} 358 \mathrm{C} / Y 358 \mathrm{C}}$ mice may destabilize the fear trace (Akers et al, 2014), yet in our mice this was not linearly related to contextual fear memory. Our findings suggest that PDE4B inhibition is a putative therapeutic approach in overly persistent fear memories, typified by post-traumatic stress disorder, which would benefit from a larger prophylactic window.

In summary, the $\mathrm{Y} 358 \mathrm{C}$ reduced-function $\mathrm{PDE} 4 \mathrm{~B}$ mutant resulted in increased phosphorylation of CREB, decreased binding of PDE4B to DISC1, and upregulation of DISC1 and $\beta$-Arrestin in the hippocampus and amygdala. PDE4B ${ }^{\mathrm{Y} 358 \mathrm{C} / \mathrm{Y} 358 \mathrm{C}}$ mice displayed a phenotype of decreased anxiety, increased exploration, and cognitive enhancement across several tests of learning and memory, in parallel with hippocampal synaptic changes including enhanced LTP, impaired depotentiation, and enhanced neurogenesis. Contextual fear memory, though intact at $24 \mathrm{~h}$, was decreased at 7 days and replicated pharmacologically with a non-selective PDE4 inhibitor. Our data establish specific inhibition of PDE4B as a promising therapeutic approach for disorders of memory and anxiety. Future studies should examine the neural and behavioral effects of brain-penetrant PDE4Bselective inhibitors in psychiatric and neurologic models.

\section{FUNDING AND DISCLOSURE}

This work was supported in part by grants from the Canadian Institutes of Health Research (MOP-111198; to JCR), the United Kingdom Medical Research Council (G0900625) and the National Alliance for Research on Schizophrenia and Depression (to SJC). JCR holds a Canada Research Chair in Learning and Memory. The remaining authors declare no conflict of interests.

\section{ACKNOWLEDGMENTS}

We thank Deen Quwailid for help with screening the MRC Harwell ENU archive, and John Rodgers for critical reading of the manuscript.

\section{REFERENCES}

Ahmed T, Frey JU (2005). Phosphodiesterase 4B (PDE4B) and cAMP-level regulation within different tissue fractions of rat hippocampal slices during long-term potentiation in vitro. Brain Res 1041: 212-222.

Akers KG, Martinez-Canabal A, Restivo L, Yiu AP, De Cristofaro A, Hsiang HL et al (2014). Hippocampal neurogenesis regulates forgetting during adulthood and infancy. Science 344: 598-602.

Albensi BC, Oliver DR, Toupin J, Odero G (2007). Electrical stimulation protocols for hippocampal synaptic plasticity and neuronal hyper-excitability: are they effective or relevant? Exp Neurol 204: 1-13.
Baillie GS (2009). Compartmentalized signalling: spatial regulation of cAMP by the action of compartmentalized phosphodiesterases. Febs J 276: 1790-1799.

Baillie GS, MacKenzie SJ, McPhee I, Houslay MD (2000). Sub-family selective actions in the ability of Erk2 MAP kinase to phosphorylate and regulate the activity of PDE4 cyclic AMPspecific phosphodiesterases. Br J Pharmacol 131: 811-819.

Baillie GS, Sood A, McPhee I, Gall I, Perry SJ, Lefkowitz RJ et al (2003). beta-Arrestin-mediated PDE4 cAMP phosphodiesterase recruitment regulates beta-adrenoceptor switching from Gs to Gi. Proc Natl Acad Sci USA 100: 940-945.

Bekinschtein P, Cammarota M, Igaz LM, Bevilaqua LR, Izquierdo I, Medina JH (2007). Persistence of long-term memory storage requires a late protein synthesis- and BDNF- dependent phase in the hippocampus. Neuron 53: 261-277.

Blackwood DH, Fordyce A, Walker MT St, Clair DM, Porteous DJ, Muir WJ (2001). Schizophrenia and affective disorders-cosegregation with a translocation at chromosome $1 \mathrm{q} 42$ that directly disrupts brain-expressed genes: clinical and P300 findings in a family. Am J Hum Genet 69: 428-433.

Cherry JA, Davis RL (1999). Cyclic AMP phosphodiesterases are localized in regions of the mouse brain associated with reinforcement, movement, and affect. J Comp Neurol 407: 287-301.

Cheung YF, Kan Z, Garrett-Engele P, Gall I, Murdoch H, Baillie GS et al (2007). PDE4B5, a novel, super-short, brain-specific cAMP phosphodiesterase-4 variant whose isoform-specifying N-terminal region is identical to that of cAMP phosphodiesterase-4D6 (PDE4D6). J Pharmacol Exp Ther 322: 600-609.

Davis JA, Gould TJ (2005). Rolipram attenuates MK-801-induced deficits in latent inhibition. Behav Neurosci 119: 595-602.

de Lima MN, Presti-Torres J, Garcia VA, Guimaraes MR, Scalco FS, Roesler R et al (2008). Amelioration of recognition memory impairment associated with iron loading or aging by the type 4specific phosphodiesterase inhibitor rolipram in rats. Neuropharmacology 55: 788-792.

Fatemi SH, King DP, Reutiman TJ, Folsom TD, Laurence JA, Lee S et al (2008). PDE4B polymorphisms and decreased PDE4B expression are associated with schizophrenia. Schizophr Res 101: 36-49.

Feng G, Mellor RH, Bernstein M, Keller-Peck C, Nguyen QT, Wallace $M$ et al (2000). Imaging neuronal subsets in transgenic mice expressing multiple spectral variants of GFP. Neuron 28: 41-51.

Fujimaki K, Morinobu S, Duman RS (2000). Administration of a cAMP phosphodiesterase 4 inhibitor enhances antidepressantinduction of BDNF mRNA in rat hippocampus. Neuropsychopharmacology 22: 42-51.

Ghavami A, Hirst WD, Novak TJ (2006). Selective phosphodiesterase (PDE)-4 inhibitors: a novel approach to treating memory deficit? Drugs R D 7: 63-71.

Gong B, Vitolo OV, Trinchese F, Liu S, Shelanski M, Arancio O (2004). Persistent improvement in synaptic and cognitive functions in an Alzheimer mouse model after rolipram treatment. J Clin Invest 114: 1624-1634.

Goto T, Shiina A, Yoshino T, Mizukami K, Hirahara K, Suzuki O et al (2013). Identification of the fused bicyclic 4-amino-2phenylpyrimidine derivatives as novel and potent PDE4 inhibitors. Bioorg Med Chem Lett 23: 3325-3328.

Grunwald IC, Korte M, Wolfer D, Wilkinson GA, Unsicker K, Lipp HP et al (2001). Kinase-independent requirement of EphB2 receptors in hippocampal synaptic plasticity. Neuron 32: 1027-1040.

Guan F, Zhang C, Wei S, Zhang H, Gong X, Feng J et al (2012). Association of PDE4B polymorphisms and schizophrenia in Northwestern Han Chinese. Hum Genet 131: 1047-1056.

Ikeda K, Satake S, Onaka T, Sugimoto H, Takeda N, Imoto K et al (2013). Enhanced inhibitory neurotransmission in the cerebellar cortex of Atp1a3-deficient heterozygous mice. J Physiol 591 (Pt 13): 3433-3449. 
Kahler AK, Otnaess MK, Wirgenes KV, Hansen T, Jonsson EG, Agartz I et al (2010). Association study of PDE4B gene variants in Scandinavian schizophrenia and bipolar disorder multicenter case-control samples. Am J Med Genet B Neuropsychiatr Genet 153B: 86-96.

Kirshenbaum GS, Dawson N, Mullins JG, Johnston TH, Drinkhill MJ, Edwards IJ et al (2013). Alternating hemiplegia of childhood-related neural and behavioural phenotypes in $\mathrm{Na}+\mathrm{K}+$-ATPase alpha3 missense mutant mice. PLoS One 8: e60141.

Lakics V, Karran EH, Boess FG (2010). Quantitative comparison of phosphodiesterase mRNA distribution in human brain and peripheral tissues. Neuropharmacology 59: 367-374.

LeDoux JE (2000). Emotion circuits in the brain. Annu Rev Neurosci 23: $155-184$.

Lee FH, Fadel MP, Preston-Maher K, Cordes SP, Clapcote SJ, Price DJ et al (2011). Disc1 point mutations in mice affect development of the cerebral cortex. J Neurosci 31: 3197-3206.

Li LX, Cheng YF, Lin HB, Wang C, Xu JP, Zhang HT (2011a). Prevention of cerebral ischemia-induced memory deficits by inhibition of phosphodiesterase-4 in rats. Metab Brain Dis 26: 37-47.

Li Y, Li H, Liu X, Bao G, Tao Y, Wu Z et al (2009a). Regulation of amygdalar PKA by beta-arrestin-2/phosphodiesterase- 4 complex is critical for fear conditioning. Proc Natl Acad Sci USA 106: 21918-21923.

Li YF, Cheng YF, Huang Y, Conti M, Wilson SP, O'Donnell JM et al (2011b). Phosphodiesterase-4D knock-out and RNA interferencemediated knock-down enhance memory and increase hippocampal neurogenesis via increased cAMP signaling. J Neurosci 31: $172-183$.

Li YF, Huang Y, Amsdell SL, Xiao L, O’Donnell JM, Zhang HT (2009b). Antidepressant- and anxiolytic-like effects of the phosphodiesterase- 4 inhibitor rolipram on behavior depend on cyclic AMP response element binding protein-mediated neurogenesis in the hippocampus. Neuropsychopharmacology 34: 2404-2419.

Light KR, Grossman H, Kolata S, Wass C, Matzel LD (2011). General learning ability regulates exploration through its influence on rate of habituation. Behav Brain Res 223: 297-309.

Light KR, Kolata S, Hale G, Grossman H, Matzel LD (2008). Upregulation of exploratory tendencies does not enhance general learning abilities in juvenile or young-adult outbred mice. Neurobiol Learn Mem 90: 317-329.

Marchetti C, Tafi E, Middei S, Rubinacci MA, Restivo L, Ammassari-Teule M et al (2010). Synaptic adaptations of CA1 pyramidal neurons induced by a highly effective combinational antidepressant therapy. Biol Psychiatry 67: 146-154.

Matzel LD, Townsend DA, Grossman H, Han YR, Hale G, Zappulla M et al (2006). Exploration in outbred mice covaries with general learning abilities irrespective of stress reactivity, emotionality, and physical attributes. Neurobiol Learn Mem 86: 228-240.

Menniti FS, Faraci WS, Schmidt CJ (2006). Phosphodiesterases in the CNS: targets for drug development. Nat Rev Drug Discov 5: 660-670.

Millar JK, Pickard BS, Mackie S, James R, Christie S, Buchanan SR et al (2005). DISC1 and PDE4B are interacting genetic factors in schizophrenia that regulate cAMP signaling. Science 310: 1187-1191.

Mori F, Perez-Torres S, De Caro R, Porzionato A, Macchi V, Beleta J et al (2010). The human area postrema and other nuclei related to the emetic reflex express cAMP phosphodiesterases 4B and 4D. J Chem Neuroanat 40: 36-42.

Murdoch H, Mackie S, Collins DM, Hill EV, Bolger GB, Klussmann E et al (2007). Isoform-selective susceptibility of DISC1/phosphodiesterase- 4 complexes to dissociation by elevated intracellular cAMP levels. J Neurosci 27: 9513-9524.

Naganuma K, Omura A, Maekawara N, Saitoh M, Ohkawa N, Kubota $\mathrm{T}$ et al (2009). Discovery of selective PDE4B inhibitors. Bioorg Med Chem Lett 19: 3174-3176.
Numata S, Ueno S, Iga J, Song $\mathrm{H}$, Nakataki M, Tayoshi $\mathrm{S}$ et al (2008). Positive association of the PDE4B (phosphodiesterase 4B) gene with schizophrenia in the Japanese population. J Psychiatr Res 43: 7-12.

Paspalas CD, Wang M, Arnsten AF (2013). Constellation of $\mathrm{HCN}$ channels and cAMP regulating proteins in dendritic spines of the primate prefrontal cortex: potential substrate for working memory deficits in schizophrenia. Cereb Cortex 23: 1643-1654.

Perez-Torres S, Miro X, Palacios JM, Cortes R, Puigdomenech P, Mengod G (2000). Phosphodiesterase type 4 isozymes expression in human brain examined by in situ hybridization histochemistry and $[3 \mathrm{H}]$ rolipram binding autoradiography. Comparison with monkey and rat brain. J Chem Neuroanat 20: 349-374.

Pickard BS, Thomson PA, Christoforou A, Evans KL, Morris SW, Porteous DJ et al (2007). The PDE4B gene confers sex-specific protection against schizophrenia. Psychiatr Genet 17: 129-133.

Porteous DJ, Thomson PA, Millar JK, Evans KL, Hennah W, Soares DC et al (2014). DISC1 as a genetic risk factor for schizophrenia and related major mental illness: response to Sullivan. Mol Psychiatry 19: 141-143.

Rastogi A, Zai C, Likhodi O, Kennedy JL, Wong AH (2009). Genetic association and post-mortem brain mRNA analysis of DISC1 and related genes in schizophrenia. Schizophr Res 114: 39-49.

Reyes-Irisarri E, Perez-Torres S, Miro X, Martinez E, Puigdomenech P, Palacios JM et al (2008). Differential distribution of PDE4B splice variant mRNAs in rat brain and the effects of systemic administration of LPS in their expression. Synapse $\mathbf{6 2}$ : 74-79.

Richter W, Menniti FS, Zhang HT, Conti M (2013). PDE4 as a target for cognition enhancement. Expert Opin Ther Targets 17: 1011-1027.

Richter W, Unciuleac L, Hermsdorf T, Kronbach T, Dettmer D (2001). Identification of inhibitor binding sites of the cAMPspecific phosphodiesterase 4. Cell Signal 13: 287-297.

Robichaud A, Stamatiou PB, Jin SL, Lachance N, MacDonald D, Laliberte F et al (2002). Deletion of phosphodiesterase 4D in mice shortens alpha(2)-adrenoceptor-mediated anesthesia, a behavioral correlate of emesis. J Clin Invest 110: 1045-1052.

Rutten K, Wallace TL, Works M, Prickaerts J, Blokland A, Novak TJ et al (2011). Enhanced long-term depression and impaired reversal learning in phosphodiesterase 4B-knockout (PDE4B $(-/-))$ mice. Neuropharmacology 61: 138-147.

Rutter AR, Poffe A, Cavallini P, Davis TG, Schneck J, Negri M et al (2014). GSK356278, a potent, selective, brain-penetrant phosphodiesterase 4 inhibitor that demonstrates anxiolytic and cognitionenhancing effects without inducing side effects in preclinical species. J Pharmacol Exp Ther 350: 153-163.

Saab BJ, Georgiou J, Nath A, Lee FJ, Wang M, Michalon A et al (2009). NCS-1 in the dentate gyrus promotes exploration, synaptic plasticity, and rapid acquisition of spatial memory. Neuron 63: 643-656.

Shepherd M, McSorley T, Olsen AE, Johnston LA, Thomson NC, Baillie GS et al (2003). Molecular cloning and subcellular distribution of the novel PDE4B4 cAMP-specific phosphodiesterase isoform. Biochem J 370(Pt 2): 429-438.

Silvestre JS, Fernandez AG, Palacios JM (1999). Effects of rolipram on the elevated plus-maze test in rats: a preliminary study. J Psychopharmacol 13: 274-277.

Siuciak JA, Chapin DS, McCarthy SA, Martin AN (2007). Antipsychotic profile of rolipram: efficacy in rats and reduced sensitivity in mice deficient in the phosphodiesterase-4B (PDE4B) enzyme. Psychopharmacology (Berl) 192: 415-424.

Siuciak JA, McCarthy SA, Chapin DS, Martin AN (2008). Behavioral and neurochemical characterization of mice deficient in the phosphodiesterase-4B (PDE4B) enzyme. Psychopharmacology (Berl) 197: 115-126. 
Slipczuk L, Tomaiuolo M, Garagoli F, Weisstaub N, Katche C, Bekinschtein P et al (2013). Attenuating the persistence of fear memory storage using a single dose of antidepressant. Mol Psychiatry 18: 7-8.

Smith DL, Pozueta J, Gong B, Arancio O, Shelanski M (2009). Reversal of long-term dendritic spine alterations in Alzheimer disease models. Proc Natl Acad Sci USA 106: 16877-16882.

Stupien G, Florian C, Roullet P (2003). Involvement of the hippocampal CA3-region in acquisition and in memory consolidation of spatial but not in object information in mice. Neurobiol Learn Mem 80: 32-41.

Sung BJ, Hwang KY, Jeon YH, Lee JI, Heo YS, Kim JH et al (2003). Structure of the catalytic domain of human phosphodiesterase 5 with bound drug molecules. Nature 425: 98-102.

Tomppo L, Hennah W, Lahermo P, Loukola A, Tuulio-Henriksson A, Suvisaari J et al (2009). Association between genes of disrupted in schizophrenia 1 (DISC1) interactors and schizophrenia supports the role of the DISC1 pathway in the etiology of major mental illnesses. Biol Psychiatry 65: 1055-1062.

Tully T, Bourtchouladze R, Scott R, Tallman J (2003). Targeting the CREB pathway for memory enhancers. Nat Rev Drug Discov 2: 267-277.

Vyas A, Kim SK, Giacomini N, Boothroyd JC, Sapolsky RM (2007). Behavioral changes induced by Toxoplasma infection of rodents are highly specific to aversion of cat odors. Proc Natl Acad Sci USA 104: 6442-6447.

Zhang HT (2009). Cyclic AMP-specific phosphodiesterase-4 as a target for the development of antidepressant drugs. Curr Pharm Des 15: 1688-1698.

Zhang HT, Crissman AM, Dorairaj NR, Chandler LJ, O’Donnell JM (2000). Inhibition of cyclic AMP phosphodiesterase (PDE4) reverses memory deficits associated with NMDA receptor antagonism. Neuropsychopharmacology 23: 198-204.

Zhang HT, Huang Y, Masood A, Stolinski LR, Li Y, Zhang L et al (2008). Anxiogenic-like behavioral phenotype of mice deficient in phosphodiesterase 4B (PDE4B). Neuropsychopharmacology 33: 1611-1623.

(c) (i) This work is licensed under a Creative Commons Attribution 4.0 International License. The images or other third party material in this article are included in the article's Creative Commons license, unless indicated otherwise in the credit line; if the material is not included under the Creative Commons license, users will need to obtain permission from the license holder to reproduce the material. To view a copy of this license, visit http://creativecommons.org/licenses/ by/4.0/

Supplementary Information accompanies the paper on the Neuropsychopharmacology website (http://www.nature.com/npp) 